\title{
Ação afirmativa nos Estados Unidos: breve sintese da jurisprudência e da pesquisa social científica
}

RIGHARD LEMPERT*

\section{Resumo}

Este artigo pretende apresentar sucintamente aos leitores não familiarizados com a ação afirmativa nos Estados Unidos seus antecedentes históricos e atual status legislativo e, de maneira mais abrangente, abordar questões empíricas das ciências sociais relacionadas com a ação afirmativa. Abordam-se especificamente as falhas e/ou limitações da pesquisa que sustenta a hipótese da disparidade educacional, da evidência empírica da "disparidade científica", e a afirmação de que a ação afirmativa baseada em classe social seria tão ou quase tão eficaz na promoção da diversidade racial quanto a ação afirmativa baseada em raça. Examinam-se especificamente os trabalhos de Richard Sander, Richard Kahlenberg, Doug Williams e Peter Arcidiacono. O artigo também afirma que o caso Bakke, que apresentou, pela primeira vez, uma decisão da Suprema Corte sobre a ação afirmativa, desvirtuou a jurisprudência a respeito da ação afirmativa na educação e as discussões sobre o tema, de modo a provocar efeitos lamentáveis e duradouros.

Palavras-chave: Raça. Classe social. Diversidade racial. Educação superior. Discriminação positiva.

\footnotetext{
* Universidade de Michigan (Estados Unidos).
} 
Sociologias, Porto Alegre, ano 17, no 40, set/dez 2015, p. 34-91

\section{Affirmative Action in the United States: A Short Summary of the Law and Social Science**}

\section{Abstract}

This paper, seeks to briefly acquaint readers unfamiliar with affirmative action in the United States with its historical background and current legal status, and in a more extended way on the empirical social science addressing issues related to affirmative action. It specifically addresses and shows the flaws in and/ or limitations of research that supports the educational mismatch hypothesis, the empirical case for "science mismatch," and the claim that class-based affirmative action would be as or almost as effective in promoting racial diversity as race-based affirmative action. Work by Richard Sander, Richard Kahlenberg, Doug Williams and Peter Arcidiacono is specifically addressed. The article also argues that the Bakke case, which first put the Supreme Court's imprimatur on affirmative action, distorted the jurisprudence of educational affirmative action and conversations about it in ways that have had lasting, unfortunate effects.

Keywords: Race. Class. Racial diversity. Higher education. Positive discrimination.

\section{Introdução}

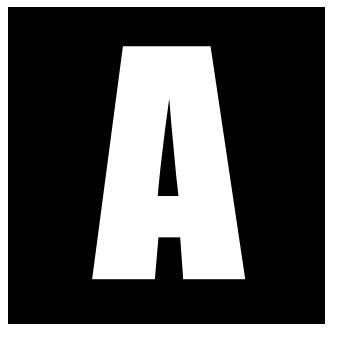

ação afirmativa nos Estados Unidos tem ajudado diversos grupos, incluindo veteranos, mulheres e minorias étnico-raciais. Já assumiu diferentes formas, desde publicidade dirigida até quotas de fato, e tem sido utilizada em esferas variadas, incluindo emprego, contratos do governo e educação superior. Restrições de espaço neste artigo forçam-me a concentrar atenção sobre ação afirmativa na educação superior. Ao fazê-lo, discutirei brevemente sua história e a jurisprudência pertinente,

${ }^{* *}$ Tradução Carolina Fernandes. Revisão técnica Karl Monsma. 
mas vou concentrar-me principalmente nas controvérsias empíricas sobre consequências educacionais das ações afirmativas para seus supostos beneficiários, em particular os negros. A ação afirmativa assume muitas formas na educação superior dos Estados Unidos, incluindo a divulgação direcionada e programas preparatórios especiais para os estudos universitários. Contudo, as controvérsias sobre as quais vou concentrar-me dizem respeito às consequências da seleção, para estudo em instituições de maioria branca, de negros (e outras minorias, predominantemente latinos e indígenas) cujas qualificações acadêmicas (ou seja, histórico escolar e escores nos exames de admissão) são inferiores e, muitas vezes, bastante inferiores aos da maioria dos brancos selecionados. Uma vez que a maior parte da literatura empírica se concentra nos negros, minha discussão também o fará, mas muito do que escrevo também se aplica aos beneficiários latinos e indígenas das ações afirmativas.

\section{Ação afirmativa na Educação Superior}

\section{Contexto e Necessidade}

A maioria das instituições americanas de ensino superior não é seletiva. Elas não promovem ações afirmativas, porque ou tendem a admitir praticamente qualquer candidato disposto a pagar seus custos, ou têm suficientes candidatos de minorias que atendem seus requisitos usuais de admissão, tornando a ação afirmativa desnecessária para garantir representação significativa das minorias no corpo estudantil. Em outras universidades e faculdades, contudo, inclusive nas mais prestigiosas, se as admissões fossem baseadas apenas em resultados de testes e históricos de desempenho - segundo muitos, as melhores medidas objetivas disponíveis de mérito acadêmico - o número de negros nessas universidades 
seria absolutamente pequeno e proporcionalmente muito menor do que sua proporção na população. Para dar apenas um exemplo, a Faculdade de Direito da Universidade de Michigan, onde lecionei por muitos anos, orgulhava-se de ser possivelmente a primeira faculdade de direito do país a admitir estudantes negros e, ao longo de boa parte de sua história, uma turma típica poderia ter várias faces negras. Assim, 25 dos 1.983 estudantes (ou 1,3\%) formados em Michigan entre 1950 e 1957eram afro-americanos. Todavia, nas próximas 12 turmas de formandos, apenas 5 estudantes (ou $0,02 \%$ ) eram negros ${ }^{1}$.

Isso não se deu porque os afro-americanos candidatos a Michigan fossem academicamente mais fracos do que anteriormente; mas porque o número de candidatos brancos com qualificações acadêmicas mais fortes do que as apresentadas por quase todos os candidatos negros aumentou tanto que havia um número mais do que suficiente desses brancos altamente qualificados para completar cada nova turma². A situação era

\footnotetext{
${ }^{1}$ Os dados foram extraídos da evidência apresentada durante o julgamento do caso Grutter v. Bollinger, uma ação judicial que buscou derrubar o programa de ação afirmativa da Faculdade de Direito. A Michigan não era diferente da maioria de suas pares na escassez de matrículas de estudantes negros em meados dos anos 1960. Na Faculdade de Direito Boalt Hall (da Universidade da Califórnia) as quatro turmas que ingressaram entre 1963 e 1966 incluíram, no total, matrículas de 5 estudantes negros(as). Na UCLA, durante este período, o total de matrículas foi de 1. A Faculdade de Direito de Harvard rompeu com este modelo, talvez porque os poucos estudantes de direito negros que poderiam ter entrado nas universidades de Michigan, UCLA ou Berkeley tenham se qualificado também para Harvard e preferiram ir para lá (Kidder, 2003, p.10) [Nota de esclarecimento a respeito de minha própria atuação quanto a esta questão: Fui o autor principal da política de ação afirmativa da Faculdade de Direito da Universidade de Michigan, alvos de questionamento no caso Grutter, e participei, desde então, de várias intervenções amicus curiae de orientação empírica, buscando defender a constitucionalidade das ações afirmativas.]

${ }^{2}$ Isso pode ser reflexo, também, da crescente importância das notas no Law School Admission Test (LSAT), o exame nacional para ingresso às faculdades de direito, como critério de admissão (Kidder, 2003). Em relação aos brancos, os candidatos a faculdades de direito pertencentes a minorias étnico-raciais tendem a apresentar tanto notas mais baixas no LSAT, como uma média mais baixa nas notas da graduação, mas a disparidade nas notas do LSAT é maior.
} 
parecida nas mais concorridas faculdades de graduação, profissionais* e de pós-graduação em todo o país. A disparidade racial nas qualificações para ingresso tem suas raízes na história americana de discriminação racial. No sul do país, a segregação implicava uma educação muito inferior em qualidade para a maioria dos afro-americanos do que aquela recebida pela maioria dos brancos. No norte, a concentração geográfica da pobreza e o sistema de financiamento da escola pública fundamental e média (da pré-escola à 12a série), por meio de impostos sobre a propriedade imobiliária local, teve efeitos semelhantes. Universidades e Faculdades seletivas responderam aos seus extremamente baixos números de matrículas de negros e à percepção de que desigualdade e injustiça eram a causa disso, com a instituição de programas de ação afirmativa. Um programa típico fazia a busca ativa de estudantes afro-americanos, estimulando-os a candidatarem-se, e os candidatos considerados mais capazes de atender aos requisitos acadêmicos da faculdade eram admitidos, mesmo quando seus históricos escolares e notas nos exames de seleção fossem inferiores, e frequentemente muito inferiores, às qualificações acadêmicas da maioria dos estudantes brancos admitidos ${ }^{3}$.

\footnotetext{
*Nos EUA, muitos dos cursos de formação profissional, como os de medicina, odontologia, direito, administração ou jornalismo, são exclusivamente de pós-graduação, e são administrados por faculdades específicas dentro das universidades (referidos como professional schools - law school, medical school, school of business administration, etc.). O ingresso a muitas dessas faculdades profissionais é altamente disputado, e os escores de exames específicos nacionalmente padronizados, como o LSAT (para as faculdades de direito), e a média dos conceitos da graduação são de longe os dois critérios mais importantes nas decisões de seleção. O termo graduate school (pós-graduação), por outro lado, geralmente se refere aos cursos de pós-graduação acadêmicos, orientados para a pesquisa e a formação de professores universitários [Nota do organizador].

${ }^{3}$ Em alguns anos, havia menos de 40 estudantes negros em todo o país com notas no LSAT altas o suficiente para thes propiciar uma boa chance de serem aceitos por uma das dez faculdades de direito mais seletivas, em seleções universais, e alguns desses podem ter tido sua admissão negada com base em seus históricos escolares da graduação. Mas muitos outros estudantes negros podem ter tido notas e classificação no LSAT melhores do que aquelas de alguns dos estudantes brancos admitidos, porque uma faculdade de direito altamente seletiva pode re-
} 
Pode-se dizer que, no início, as universidades e faculdades eram excessivamente otimistas quanto à capacidade dos estudantes negros aceitos, em apresentar um alto nível de desempenho. Na Faculdade de Direito da Universidade de Michigan, onde lecionei, quando os professores aprovaram o programa de ação afirmativa, muitos acreditavam que sua superioridade didática contribuiria em muito para compensar as deficiências acadêmicas apontadas pelos resultados dos exames e dos históricos escolares dos negros admitidos. Mas isso não aconteceu. As notas da maioria dos afro-americanos admitidos por ação afirmativa os colocavam nos últimos lugares de sua turma. Alguns desistiram, outros não atingiram a média necessária para passar de ano ou para se formar, e ainda outros conseguiram graduar-se, mas foram reprovados no exame da ordem. Problemas de baixo desempenho não estavam restritos às Faculdades de Direito ou à Universidade de Michigan. Universidades e consórcios de universidades, incluindo cursos de graduação e faculdades profissionais, desenvolveram programas de recuperação, de verão e durante o período letivo, com o objetivo de adaptar estudantes negros à cultura e rigor acadêmicos dos campi predominantemente brancos, e de ajudá-los a desenvolver habilidades que os estudantes brancos, com qualificações acadêmicas mais fortes, pareciam já possuir.

Ainda assim, mesmo nos primeiros anos da ação afirmativa, certo número de estudantes afro-americanos conseguiu sobreviver aos rigores das faculdades que frequentavam, recebendo títulos que lhes deram uma vantagem ao sair da universidade para o mundo do trabalho e alguns realmente prosperaram. A julgar pelo que vi na instituição onde leciona-

servar algumas vagas para filhos de ex-alunos ricos (cujas doações são uma fonte importante de financiamento para essas faculdades) ou, no caso de faculdades públicas, para alunos protegidos por políticos poderosos. Essas preferências não-raciais eram mais comuns no nível da graduação, pois um número maior de "herdeiros" de ex-alunos ricos se beneficiava das preferências nesse nível, assim como atletas que jogam nos times das universidades. 
va, era difícil distinguir, na etapa da seleção, quem conseguiria graduar-se sem muita dificuldade, mesmo estando entre os últimos da turma, e quem enfrentaria muita dificuldade, talvez fosse reprovado ou jamais passaria no exame da ordem, caso conseguisse graduar-se. Em resposta a isso, a faculdade impôs requisitos mínimos mais estritos para os ingressantes por ação afirmativa, determinou maior atenção do corpo docente a algumas de suas necessidades, além de aumentar progressivamente o número de estudantes negros nas novas turmas, o que pode ter criado um clima mais confortável. Apesar da tendência continuada de desempenho acadêmico dos estudantes afro-americanos da Michigan os colocar de forma desproporcionada entre os últimos de cada turma, logo havia muito menos provas desastrosas e a percepção de que alguns dos admitidos não poderiam tornar-se bons advogados desapareceu, pois já não era verdade (Lempert et al, 2000). Enquanto esse tipo de ajustes ocorria em minha universidade, mudanças similares nas admissões e políticas de apoio ocorriam nos cursos de graduação e faculdades profissionais mais seletivas de todo o país. Multiplicou-se o número de negros que se formou nessas universidades e faculdades e, como veremos, as evidências indicam que muitos daqueles que sem a ação afirmativa não teriam acesso a uma universidade seletiva alcançaram considerável sucesso posterior na vida profissional, contribuindo para o desenvolvimento de uma classe média afro-americana bem instruída.

Nos primórdios dos programas de ação afirmativa, a imagem predominante dos afro-americanos era de um povo empobrecido em razão da história de discriminação racial histórica e de uma sociedade que, em algumas regiões do país, ainda lutava por manter a subordinação dos negros. A ação afirmativa para afro-americanos era considerada promotora não apenas de justiça racial, mas também da equidade de classe. Tal visão não estava completamente equivocada, pois, quando as palavras "afro- 
-americano" ou "negro" eram usadas para modificar "classe média" ou "elite", referiam-se a um grupo que, pela maioria dos parâmetros econômicos e sociais, não era tão abastado - especialmente em relação à riqueza acumulada - quanto aqueles das classes média e alta brancas. Ainda assim, mesmo no início da ação afirmativa, seus beneficiários frequentemente vinham de famílias que se viam como classe média ou até alta, e suas atitudes em relação à educação e a sua capacidade de proporcionar aos filhos oportunidades, educacionais e de outros tipos, frequentemente refletiam seu status de classe. Embora os filhos dos afro-americanos mais ricos não fossem os alvos vislumbrados nos primórdios dos programas de ação afirmativa, eles eram os estudantes com maior probabilidade de sentirem-se à vontade nos campi predominantemente brancos, e seriam os mais bem preparados para os rigores da educação nas melhores universidades. Contudo, mesmo este grupo de candidatos afro-americanos precisava, com frequência, do apoio da ação afirmativa para assegurar seu ingresso nas universidades ou faculdades onde pretendiam estudar ${ }^{4}$.

\footnotetext{
${ }^{4}$ Os afro-americanos diferem dos brancos pobres que poderiam se beneficiar se existissem ações afirmativas baseadas na classe social pelo fato de esses últimos ganharem diplomas que Ihes possibilitarão escapar de suas origens de classe. Mas, com exceção daqueles que realizam esforços persistentes e bem-sucedidos para "passar" como brancos, os negros mantêm o status que os qualificou para a ação afirmativa: ou seja, continuam sendo negros. Pessoas negras com alta escolaridade quase inevitavelmente viram bons exemplos para outros e também alvos de discriminação, e as mais bem-sucedidas são, muitas vezes, aquelas a quem os governos e as organizações sociais buscam quando precisam de uma voz negra. Num estudo da vida profissional dos ex-alunos de grupos minoritários formados pela Faculdade de Direito da Universidade de Michigan que estavam atuando profissionalmente, David Chambers, Terry Adams e eu mesmo (2000, p.488) apuramos que entre os afro-americanos, a maior parte dos quais se beneficiou de ação afirmativa, muitos estavam engajados em atividades de liderança, representação pro bono e outras formas de serviços comunitários, em número proporcionalmente muito maior do que os brancos ou de outras minorias. A diferença reside na vantagem usufruída pelas pessoas negras que possuem diploma.
} 


\section{Lei e Jurisprudência}

Desde o princípio, a ação afirmativa com base na raça gerou controvérsias. Por um lado, porque alguns brancos acharam que reduziria as chances de seus filhos serem aceitos nas universidades onde queriam estudar; por outro, porque utilizar a raça para dar vantagem a um grupo em detrimento de outro não só contrariava a ideologia meritocrática propalada pelas instituições da elite, como parecia incoerente com a ideia de igualdade racial ${ }^{5}$. No início, poucos acreditavam que as admissões por ação afirmativa poderiam conflitar com a 14를 Emenda à Constituição dos Estados Unidos*. Mas, em 1974, os defensores da política acordaram para essa possibilidade, quando o caso DeFunis v. Odegaard (1974) foi indeferido como irrelevante, pela Suprema Corte, por uma votação apertada de 5-4. Os quatro dissidentes, liderados pelo renomado juiz liberal ${ }^{* *}$ William O. Douglas, teriam ouvido o caso e, provavelmente, teriam julgado inconstitucional a ação afirmativa ${ }^{6}$. Os juízes não poderiam continuar evitando esse tema por muito tempo. No entanto, quando o encararam novamente - no caso Regents of the University of California v. Bakke

\footnotetext{
${ }^{5}$ Sem dúvida, o persistente racismo por parte dos brancos também afetou e continua a afetar as atitudes frente a ações afirmativas.

* Passada em 1868, logo depois da Guerra Civil, com a intenção de garantir a cidadania e os direitos dos negros recém libertados da escravidão, a 14a Emenda declara, entre outras coisas, que todas as pessoas nascidas nos Estados Unidos são cidadãos e que todos os cidadãos têm o direito à "proteção igual" das leis. [Nota do organizador]

${ }^{* *}$ No contexto dos EUA, a qualificação do juiz como "liberal" significa que ele tinha simpatias por políticas socialdemocratas. [Nota do organizador]

${ }^{6}$ A Suprema Corte dos EUA acolhe processos concretos, e não casos em que nenhuma parte tenha um interesse em jogo. Não há, no entanto, uma definição clara que possa ser usada para decidir o que exatamente configura um litígio concreto. No caso Defunis, teria sido fácil justificar a aceitação do caso se a maioria o quisesse. Portanto, é justo supor que pelo menos alguns dos cinco juízes que votaram pelo indeferimento do caso em razão de irrelevância desejavam, pelo momento, evadir-se à questão.
} 
(1978) -, encontraram outra forma de evitar confrontar a questão fundamental. Quatro juízes julgaram procedente a demanda de Allan Bakke, um branco que se candidatou à Faculdade de Medicina, da Universidade da Califórnia - Davis ${ }^{7}$, mas teve sua admissão negada; e quatro juízes consideraram que, contanto que programas de apoio às minorias não degradem ou menosprezem os brancos, eles são constitucionais. Com essa divisão, a opinião do Juiz Powell, que emitiu o parecer final, definiu o resultado. O juiz Powell defendia que metas de admissão de minorias eram inconstitucionais se - como no sistema da Davis, que reservava 16 vagas para minorias - fossem metas ou cotas inflexíveis; mas que a ação afirmativa era constitucional se fosse necessária para promover a diversidade racial nas universidades.

Até o caso Bakke, o discurso usado para justificar a ação afirmativa era, principalmente, de igualdade, imparcialidade e de justiça restaurativa. Ninguém negava a extrema falta de representação de negros e, mais tarde, de hispânicos e de indígenas nas fileiras daqueles que possuem diplomas universitários e profissionais. Tampouco havia muita controvérsia sobre a origem da disparidade - no caso dos afro-americanos, os primeiros beneficiários da ação afirmativa, era um legado da escravidão e da discriminação que perdurou mesmo depois da abolição da escravidão legal ${ }^{8}$. O caso Bakke mudou a natureza do discurso em torno da ação afirmativa, pois os educadores deixaram de tentar justificá-la pela equidade racial e, frequentemente sem qualquer mudança

\footnotetext{
${ }^{7} \mathrm{O}$ autor do parecer deste grupo, o Juiz Stevens, estava no início de sua carreira no judiciário. $\mathrm{Na}$ época em que encerrava seu trabalho na corte, teria votado pela constitucionalidade das ações afirmativas raciais.

${ }^{8}$ Argumentos similares referidos a prejuízos impostos pelo Estado e discriminações passadas e presentes foram levantados quando da inclusão das populações hispânica e indígenas como minorias com direito a ações afirmativas.
} 
em suas práticas de admissão, passaram a promover a ação afirmativa por sua contribuição para a diversidade educacional.

Embora, para os críticos, a celebração da diversidade representasse uma farsa e uma cortina de fumaça usada para encobrir as metas maiores de políticas públicas promovidas por acadêmicos de esquerda, pesquisas estimuladas pelo argumento da diversidade do caso Bakke quase sempre encontram evidências consistentes do valor educativo de misturar nas turmas estudantes de raças diferentes (Orfield; Kurlaender, 2001; AERA, 2012). As consequências de uma maior diversidade no campus também se manifestam em programas, como os de estudos da negritude (Black Studies) e outros cursos criados, pelo menos em parte, em resposta a pressões de estudantes oriundos de minorias, e em uma grande variedade de clubes e atividades claramente promovidas por esses estudantes. Além disso, ao ampliar a diversidade estrutural, a ação afirmativa conduz não apenas ao aumento de contatos interraciais no campus e em salas de aulas, mas também à crescente diversidade nas interações informais (Pike; Kuh, 2006). Isso, por sua vez, aumenta a compreensão em relação a pessoas com experiências diferentes de sua própria (Pike; Kuy; Gonyea, 2007). Em resumo, ao serem forçadas a promover a diversidade e seus benefícios, faculdades e universidades não apenas passaram a realmente aceitar a diversidade como uma justificativa para a ação afirmativa, mas também descobriram os benefícios educacionais, antes despercebidos, trazidos pela diversidade racial e étnica.

A constitucionalidade da ação afirmativa baseada em raça foi revisitada diversas vezes na Suprema Corte desde o caso Bakke, de modo mais destacado nos casos Gratz v. Bollinger (2003), Grutter v. Bollinger (2003) e Fisher v. University of Texas (2013). Interpretados em conjunto, Gratz e Grutter ${ }^{9}$ estabelecem que, como parte de um processo de ad-

\footnotetext{
${ }^{9}$ Como presidente do Comitê de Admissões da Faculdade de Direito da Universidade de Michigan em 1990-91, fui redator principal da política de ação afirmativa da escola, a qual foi questionada no caso Grutter. Também estive profundamente envolvido no julgamento do
} 
missão holístico, a raça de um candidato pode ser levada em consideração, com o propósito de promover-se a diversidade educacional, mas nenhum número fixo de pontos ou outras vantagens constantes devem derivar automaticamente do status racial. O caso Fisher reafirmou Bakke e Grutter, mas ao contrário do que foi expresso nesse último, exigiu que os juízes examinassem cuidadosamente os programas de ação afirmativa para assegurar que esses seriam a única forma de atender as metas legítimas de diversidade. Depois da devolução para um novo julgamento, a Corte Federal de Apelações, que já havia sustentado o plano de ação afirmativa do Texas - em litígio no caso Fisher - reafirmou sua decisão anterior, e a Suprema Corte, mais uma vez, aceitou reavaliar a decisão da Corte Distrital. Pode ser que os juízes venham a estabelecer barreiras ainda mais altas para os defensores da ação afirmativa, e é possível que, num segundo exame, a maioria dos juízes venha a julgar inconstitucional a ação afirmativa baseada em raça.

\section{Pesquisa Social}

A pesquisa empírica sobre ações afirmativas tem se concentrado predominantemente em duas questões. Uma se refere aos benefícios educacionais da diversidade no campus e foca tanto no clima do campus e no que as pessoas brancas ganham com a diversidade, quanto em como as minorias se saem. Estudos que abordam essas questões estão reunidos em AERA (2012), e mencionei alguns acima. Esses, em geral, mostram os diversos tipos de efeitos positivos da diversidade. Não voltarei a eles neste texto.

caso, tanto como testemunha de parte da faculdade e, mais tarde, como testemunha pelos estudantes intervenientes que me convocaram para testemunhar sobre um estudo que conduzi juntamente com David Chambers e Terry Adams (Lempert; Chambers; Adams, 2000) sobre a prática profissional dos ex-alunos da faculdade pertencentes a minorias. 


\section{A Hipótese da disparidade}

A outra linha concentra-se nas minorias que conseguiram matricular-se em universidades seletivas com a ajuda da ação afirmativa e em seu desempenho. Essa linha tem gerado controvérsias. Tão logo iniciaram os programas de ação afirmativa, surgiram críticos alegando que essas ações mais prejudicavam do que ajudavam os estudantes afro-americanos ${ }^{10}$, pois a preferência recebida possibilitava frequentarem universidades ou faculdades onde estariam tão defasados em relação a seus colegas em termos de habilidades e de preparo, que não conseguiriam acompanhar o desempenho de outros estudantes e, assim, sofreriam psicológica e educacionalmente. Sem a ação afirmativa, argumentavam, esses alunos negros estariam em faculdades em que seu grau de habilidade seria comparável ao da maioria de seus colegas de classe e, assim, aprenderiam mais e estariam mais satisfeitos consigo mesmos (Summers, 1970; Thernstrom; Thernstrom 1997). O conservador negro Thomas Sowell (1978), comentando sobre universitários afro-americanos da Cornell com qualificações de ingresso entre as 25\% meIhores em nível nacional, mas frequentando uma universidade em que a maioria dos alunos qualificava-se entre os primeiros $1 \%$ em nível nacional, manifestou-se assim: "estudantes pertencentes a minorias, com todas as chances de sucesso em ambiente universitário normal, foram artificialmente levados ao fracasso, por estarem em descompasso com uma instituição com exigências rigorosas demais para eles".

Esses e outros críticos nomearam esse fenômeno como "disparidade" (mismatch), embora pouco tivessem além de impressões, oriundas talvez de preconceitos, para sustentar suas alegações. Suas críticas, contudo, fomentaram o interesse em estudar empiricamente o desempenho de beneficiários das ações afirmativas nas faculdades e nos níveis mais avan-

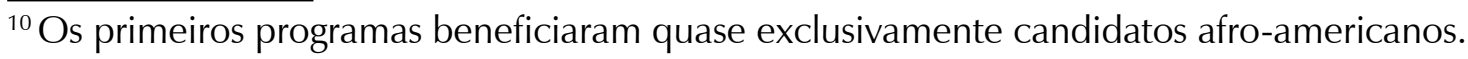


çados. Sob um aspecto, esses estudantes não se saíram bem. Os alunos que haviam ingressado em universidades ou faculdades seletivas com o benefício da ação afirmativa para minorias alcançaram notas que os colocaram entre os últimos classificados em suas turmas. Isso não é surpresa. Seu desempenho em testes padronizados de ingresso, concebidos para prever o rendimento futuro na universidade ou na faculdade profissional, com frequência ficava muito abaixo daquele de seus colegas brancos ${ }^{11} \mathrm{e}$, muitas vezes, as minorias não apenas apresentavam médias de desempenho no ensino médio ou na faculdade inferiores às dos seus colegas brancos, como também, especialmente no caso dos candidatos a faculdades de graduação, a qualidade de sua educação prévia era, em geral, inferior. As primeiras coortes de beneficiários da ação afirmativa sofriam desvantagens notáveis nesses aspectos. Mas, à medida que as universidades e faculdades foram aprimorando seus processos de seleção por ação afirmativa e estabeleceram padrões mínimos para a qualificação acadêmica daqueles que aceitavam, menos estudantes pertencentes a minorias enfrentavam grandes dificuldades para serem aprovados nas disciplinas.

\footnotetext{
${ }^{11}$ Testes padronizados como os SAT, ACT, LSAT e MCAT tendem a predizer cerca de um terço da variância das notas no primeiro ano do próximo nível de estudo para os estudantes que realizam esses testes. Isso significa que a maior parte da variância não é explicada. Os testes, no entanto, não são testes de inteligência, e a correlação não deveria ser considerada uma medida precisa da relação entre o potencial acadêmico, conforme apurado com o teste, e o aprendizado posterior, uma vez que fatos não relacionados a esses fatores são provavelmente responsáveis por uma parcela desta correlação. Um desses fatores é a ameaça de estereótipo (desempenho prejudicado pelo receio de confirmar estereótipos prevalentes a respeito do grupo, ou pela falta de autoconfiança produzida por tais estereótipos) que, no caso das minorias, pode inflar a correlação teste de admissão - notas na faculdade ao diminuir a pontuação da performance tanto nos testes de admissão como naqueles ao longo do curso. Vieses culturais presentes tanto em testes de admissão como nas avaliações ao longo dos cursos podem igualmente inflar as correlações testes de admissão-rendimento na faculdade, embora não tenham relação com o potencial acadêmico e pouca relação com o que o aluno aprende. Finalmente, se os ingressantes por ação afirmativa encontram um ambiente hostil no campus, ou enfrentam outros estressores que a maior parte dos estudantes não experimenta, o rendimento desse grupo provavelmente será diminuído e a correlação entre baixos escores de admissão e rendimento posterior deverá acentuar-se."
} 
No entanto, o desempenho dos alunos admitidos no âmbito da ação afirmativa ainda tendia a classifica-los entre os últimos de suas turmas - como seria de esperar com base na comparação de suas médias nos critérios de admissão com aquelas de seus colegas brancos.

A verdadeira questão, contudo, não são as notas que beneficiários da ação afirmativa alcançam nas disciplinas em relação àquelas de seus colegas brancos, mas se suas debilidades acadêmicas os impedirão de graduarem-se e, caso o consigam, de terem sucesso ao continuar sua educação ou ao ingressar no mercado de trabalho. A questão da disparidade é somente um adendo a essas questões mais fundamentais. Ela questiona se minorias que, com o apoio de ação afirmativa, ingressam em universidades e faculdades seletivas ou de elite teriam mais chances de se formarem e de ter sucesso na vida posterior, caso tivessem frequentado instituições de ensino superior em que as qualificações acadêmicas da maior parte dos estudantes fossem similares às suas.

\section{Bowen, Bok e Outros}

Um livro pioneiro, escrito por William Bowen e Derek Bok (1998), propôs-se a responder esta questão. Usando a base de dados College and Beyond (C\&B) coletada pela Fundação Andrew W. Mellon, os autores tiveram acesso a abundante informação sobre mais de 80.000 estudantes universitários que, como integrantes de uma de três coortes, se haviam matriculado em 28 das relativamente seletivas e mais seletivas faculdades e universidades do país. Sua análise concentra-se em estudantes brancos e negros de duas das três coortes da C\&B - aquela que iniciou a faculdade no outono de 1976 e aquela que ingressou no outono de $1989^{12}$.

\footnotetext{
${ }^{12}$ A terceira coorte iniciou seu curso de graduação no outono de 1951, bem antes de iniciarem os primeiros programas de ação afirmativa e numa época em que muito poucos afro-americanos frequentavam qualquer uma das faculdades da amostra.
} 
Ao analisar a coorte de 1989, os autores descobriram que os resultados do SAT (o exame nacional padronizado para ingresso nas faculdades de graduação) mostravam uma relação "ligeiramente positiva" com as taxas de graduação, quando os primeiros estavam agrupados em cinco faixas, variando de um escore combinado de menos de 1.000 até um de 1.300 ou mais. Verificaram também que, dentro de cada faixa, estudantes brancos tinham taxas de graduação mais elevadas que afro-americanos, com diferenças que oscilavam entre cinco e dez por cento ${ }^{13}$. Mas, dentro de cada faixa, negros de universidades e faculdades mais seletivas apresentavam taxas de graduação mais altas do que estudantes negros de instituições menos seletivas e, em quatro das cinco faixas, afro-americanos de faculdades de seletividade média apresentavam taxas de graduação mais elevadas do que aqueles das faculdades menos seletivas ${ }^{14}$. Por exemplo, na faixa média da distribuição, que inclui estudantes com escores SAT totais entre 1.100 e 1.199, graduaram-se: $87 \%$ daqueles em faculdades com média total do SAT para todo campus acima de 1.300; 78\% daqueles em faculdades com um SAT médio geral entre 1.151 e 1.300; e 72\% daqueles em faculdades com escores médios do SAT de 1.150 ou menos.

É difícil imaginar resultados menos consistentes com a teoria da disparidade. Estudantes negros de faculdades ou universidades nas quais a maioria dos estudantes brancos tem escores do SAT de 100 a 200 pontos mais elevados que os seus apresentam taxas de graduação quase iguais às de seus pares brancos ( $87 \%$ v. $90 \%$ ). No entanto, estudantes afro-americanos nas faculdades menos seletivas, com escores do SAT próximos ao

\footnotetext{
${ }^{13}$ Essas diferenças refletem, pelo menos em parte, as diferenças de escore no SAT, pois é de esperar que os estudantes afro-americanos apresentem muito mais escores próximos do mínimo de cada intervalo, especialmente na faixa de escores mais altos.

${ }^{14}$ Todas as faculdades da amostra da C\&B eram seletivas, portanto, quando Bowen e Bok falam de alto, médio e baixo estratos de seletividade, estão falando em termos relativos dentro de uma amostra das faculdades relativamente e altamente seletivas.
} 
escore médio do seu campus, saem-se bem pior do que aqueles que, segundo a teoria da disparidade, estariam fadados ao fracasso, e muito pior do que seus colegas brancos (72\% v. 85\%). Há uma série de possíveis razões para essas diferenças, a mais provável delas sendo a disponibilidade de serviços de apoio e a qualidade da vida universitária nas instituições mais seletivas. Em particular, o estrato menos seletivo nesta amostra (que inclui somente instituições relativamente ou altamente seletivas) compreende as maiores universidades públicas de pós-graduação e pesquisa (a Universidade de Michigan, a Universidade de Carolina do Norte e a Universidade Estadual da Pennsylvania) enquanto as instituições do estrato superior são todas privadas e, mais do que as do terceiro estrato, as de primeiro e segundo destacam-se por seu foco na graduação.

A alegação de que esses resultados são inconsistentes com a teoria da disparidade foi estatisticamente questionada. $\mathrm{O}$ argumento é que, devido ao viés de seleção, alunos das instituições do estrato superior seriam consideravelmente mais fortes em outras variáveis consideradas nas admissões para além dos escores no SAT, as mais prováveis entre elas sendo o histórico escolar do ensino médio, a força das cartas de recomendação e a qualidade da redação submetida como parte do dossiê da seleção. Contudo, a tendência de estudantes afro-americanos terem melhor desempenho quanto mais seletiva for a faixa em que estão inseridos continua forte e estatisticamente significante, mesmo após ajustes para escola secundária entre as 10\% melhores, gênero e status socioeconômico (Bowen; Bok, 1998, p. 381).

Em vista dos controles empregados por Bowen e Bok, é muito improvável que os efeitos opostos à disparidade identificados por eles se devessem ao viés de seleção causado por fatores não observáveis. Mas, se houvesse dúvida sobre esse resultado, ela deveria ter sido enterrada pelo trabalho posterior de Alon e Tienda (2005). Esses autores examinaram duas pesquisas longitudinais representativas e aplicaram três diferentes métodos de controle para o viés de seleção. Observando não apenas afro-americanos, mas também hispânicos, brancos e asiáticos, eles 
descobriram que "depois de serem admitidos, todos os grupos de estudantes que frequentaram instituições seletivas tinham maior propensão para formarem-se dentro de seis anos após a matrícula do que seus pares em faculdades menos seletivas" (p. 297).

Eles observaram também que as "taxas de graduação dentro de seis anos, em média, são mais elevadas em instituições seletivas do que em instituições não seletivas, o que enfraquece as alegações de que reduzir os limiares de admissão para incluir mais estudantes pertencentes a minorias reduz as taxas globais de graduação" (Alon; Tienda, 2005, p.302). Voltando-se para o conjunto de dados da C\&B utilizado por Bowen e Bok, Alon e Tienda apontam que o fato de os dados provirem apenas de estudantes de instituições relativamente seletivas limita a capacidade dos dados de testarem a hipótese de disparidade, mas que, dentro desses limites, o viés de seleção não apresenta problemas. Ao contrário, "levando-se em consideração a seleção baseada em fatores não observáveis, os ganhos dos estudantes pertencentes a minorias por frequentar as instituições mais seletivas do país são ainda maiores do que aqueles produzidos pelos outros métodos" (p.303). Suas diversas análises os levaram a "rejeitar a hipótese de disparidade para estudantes que se matricularam nas instituições mais seletivas no final dos anos 1980 e princípio dos 1990" (p.297).

Outros estudos que buscaram examinar os efeitos da disparidade no âmbito universitário, sejam no desempenho acadêmico ou em seus resultados no mercado de trabalho, igualmente não logram encontrar evidências para sustentar de maneira consistente a hipótese e, como aconteceu com Bowen e Bok, algumas vezes relatam resultados mais consistentes com o efeito oposto ao da disparidade (Arcidiacono; Koedel, 2014; Dale; Kruger, 2002; Brand; Halaby, 2006; Fisher; Massy,2007; Dale; Kruger, 2014) ${ }^{15}$.

\footnotetext{
${ }^{15}$ Outro corpus de pesquisa focado nas políticas de tracking do ensino fundamental e médio, que separam os alunos em turmas diferenciadas por suposto nível de aptidão, não só não consegue demonstrar a hipótese da disparidade, como também mostra que crianças originalmente
} 
Bowen e Bok, Alon e Tienda e outros acadêmicos buscaram verificar o desempenho de beneficiários da ação afirmativa na graduação e depois, examinando taxas de graduação e outros indicadores de sucesso, incluindo suas realizações depois de se formarem. Para fazê-lo, observaram estudantes matriculados em diversas universidades e faculdades, algumas mais seletivas do que outras, em uma coorte ou coortes específicas de admissão. Aqui, a hipótese de disparidade prevê que, mantendo constantes as qualificações para admissão, estudantes das minorias apresentariam melhores resultados se frequentassem faculdades menos seletivas, onde suas qualificações equiparar-se-iam às da maioria dos estudantes matriculados. Com exceção de algumas pesquisas controversas e infundadas discutidas abaixo, não foi isso o que a maioria dos pesquisadores encontrou. Deixando de lado parâmetros como notas e colocação na turma, que são padronizados separadamente para cada instituição, ou não há evidência de efeitos da disparidade, ou as evidências sugerem o oposto do que a hipótese sugere. Ou seja, no conjunto de estudantes admitidos em diferentes instituições, aqueles que frequentam universidades e faculdades mais seletivas tendem a apresentar melhores resultados do que aqueles de instituições menos seletivas. Uma abordagem alternativa é acompanhar longitudinalmente os graduados de uma única instituição. Nesse caso, a hipótese de disparidade prevê que aqueles admitidos através de ação afirmativa - se suas qualificações forem substancialmente inferiores às da maioria dos outros estudantes - teriam pior desempenho tanto na graduação quanto no futuro.

Dois colegas e eu testamos esta última previsão ao examinamos as trajetórias na faculdade e na prática profissional de estudantes matricu-

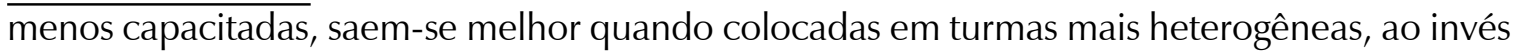
de naquelas mais homogêneas. Para uma excelente discussão sobre questões metodológicas no estudo da disparidade, bem como referência a muitos dos estudos mais relevantes, ver Camilli e Welner, (2011). 
lados na Faculdade de Direito da Universidade de Michigan, durante os primeiros 27 anos de admissões por ação afirmativa (Lempert; Chambers e Adams, 2000). A Faculdade de Direito da Universidade de Michigan foi, e ainda é, uma das faculdades de direito mais seletivas do país. Nas 27 coortes para as quais tínhamos dados, os ingressantes pertencentes a minorias não apenas apresentavam escores do LSAT substancialmente mais baixos do que os alcançados pelos ingressantes brancos, como também apresentavam, muitas vezes, médias das notas da graduação muito inferiores. No entanto, exceto com relação às notas ao longo do curso de direito, houve pouca diferença entre os resultados obtidos por graduados beneficiários da ação afirmativa e pelos demais. Não apenas as taxas de formação e de aprovação no exame da ordem eram similares, e na maior parte do período estatisticamente indistinguíveis, como também, após ajustes para tempo de formado, gênero e idade, não havia diferenças estatisticamente significantes entre a renda de beneficiários de ação afirmativa, de um lado, e de brancos ou asiáticos, de outro.

Esse resultado não se alterou quando beneficiários de ação afirmativa com melhor qualificação - estudantes que possivelmente teriam sido aceitos na Michigan sem a ação afirmativa - foram retirados da amostra. Observou-se o mesmo resultado quando a variável dependente foi satisfação com a carreira. Houve, contudo, diferenças estatisticamente significantes quando a variável dependente consistiu em um índice que combinava liderança, horas pro bono e outras formas de serviços comunitários. Beneficiários de ação afirmativa mostraram-se mais propensos a exibir escores altos nessa dimensão do que os demais, uma relação determinada principalmente pelos ex-alunos afro-americanos da faculdade. A pesquisa também revelou que, apesar de a maioria os formados por Michigan, independentemente de sua raça, ter uma clientela predominantemente branca, havia uma forte tendência de outros clientes serem 
segmentados por raça. Brancos foram consideravelmente mais propensos do que outros grupos a terem clientes brancos, afro-americanos a terem clientes negros, hispânicos a terem clientes hispânicos, indígenas a terem clientes indígenas e asiáticos a terem clientes asiáticos.

Davidson e Lewis (1997) utilizaram uma abordagem similar ao acompanhar graduados da Faculdade de Medicina da Universidade da Califórnia - Davis, durante um período de 20 anos. Seus resultados são notavelmente similares àqueles do estudo de Michigan. Eles descobriram que estudantes admitidos através do programa de ação afirmativa tiveram notas mais baixas do que as do grupo de controle constituído por estudantes admitidos regularmente, em disciplinas chave do curso de medicina. Todavia, não havia diferenças significantes entre os dois grupos no que concerne aos índices de conclusão da primeira residência escolhida, às dificuldades acadêmicas em programas de residência, honras especiais enquanto residentes, disciplinas de residência mais procuradas, certificados de especialização, características da prática profissional, envolvimento com ensino, satisfação com a escolha de medicina como carreira, escolha de especialidade médica, ou sua prática atual. Entrevistados representantes de minorias, contudo, expressaram satisfação significativamente maior com a vida de maneira geral. Esses estudos longitudinais de múltiplas turmas, como os estudos de Bowen e Bock, e de Alon e Tienda, não encontraram evidências de que as minorias sejam prejudicadas pela disparidade acadêmica.

\section{Sanders e seus críticos}

A defesa empírica dos efeitos da disparidade apoia-se amplamente nos trabalhos do Professor Richard Sander, advogado e economista, integrante do corpo docente da Faculdade de Direito da Universidade da Califórnia, Los Angeles (UCLA), e nos de alguns outros economistas ligados a ele (Sander; Taylor, 2012) ${ }^{16}$. Boa parte desse trabalho usa uma fonte de 
dados, o Bar Passage Study (BPS) - um estudo sobre aprovação no exame da Ordem dos Advogados - que dispõe de dados sobre a maioria dos integrantes da coorte de estudantes que ingressou em todas as faculdades de direito dos Estados Unidos no outono de 1991. Com algumas inevitáveis, mas administráveis, perdas amostrais, o estudo acompanha esses estudantes ao longo de seus estudos nas faculdades de direito e em suas primeiras tentativas de passar no exame.

Para fins de formulação da política hoje, a BPS é datada, já que, de acordo com a evolução dos escores do LSAT, o nível de preparo dos integrantes de minorias que e candidatam às faculdades de direito aumentou substancialmente desde 1991. Além disso, há motivos para acreditar que a relação entre os resultados do LSAT e o sucesso no curso de direito e no exame da Ordem seja uma função escalonada ao invés de contínua; ou seja, estudantes que ingressam nas faculdades de direito com resultados do LSAT abaixo de um certo nível, têm dificuldades consideráveis com os estudos e no exame da ordem, mas, uma vez ultrapassado um determinado limiar, as dificuldades diminuem muito mais do que se poderia esperar se a relação fosse linear. Isso, todavia, não destrói a relevância dos dados para testagem da hipótese da disparidade, supondo uma distribuição das qualificações acadêmicas tal como na coorte que ingressou em 1991.

O primeiro e ainda o mais citado artigo do Professor Sander atraiu especial atenção por sua surpreendente alegação de que, sem a ação afirmativa, as faculdades de direito do país teriam provavelmente produzido cerca de $14 \%$ mais advogados afro-americanos do que efetivamente produziram (Sander, 2004). O artigo é, contudo, repleto de suposições

\footnotetext{
${ }^{16}$ Tenho sido um dos críticos mais ferrenhos do Professor Sander. Certamente ele não crê que minhas opiniões sejam críticas justas ao seu trabalho, assim como acredito que são. Leitores curiosos podem querer conferir o trabalho de Sander e a pesquisa referenciada neste artigo que a questiona.
} 
Sociologias, Porto Alegre, ano 17,no 40, set/dez 2015, p. 34-91

duvidosas e de equívocos estatísticos ${ }^{17}$. Além disso, diversos pesquisadores trabalharam com os mesmos dados tentando sem sucesso replicar ou encontrar evidências que apoiassem seus resultados ${ }^{18}$. Por exemplo, Chambers et al. (2005) descobriram que, se os erros e suposições questionáveis de Sander fossem corrigidos, o número de advogados negros formados entre os estudantes ingressados nas faculdades de direito em 1991 seria de 30 a 40 por cento menor em um mundo sem ações afirmativas. Sander acusa Chambers e colegas de "fazerem as suposições mais apocalípticas possíveis" (Sander, 2005, p.2015). Mas, Rothstein e Yoon (2008), usando as próprias suposições de Sander e uma abordagem mais direta, descobriram que, se não houvesse ação afirmativa em 1991, a queda na formação de advogados negros teria sido de mais de $50 \%$ (p. 712). Outros acadêmicos que avaliaram os mesmos dados com métodos mais sofisticados encontraram pouca ou nenhuma evidência dos efeitos da disparidade (Ayres; Brooks, 2005; Ho, 2005; Camilli et al, 2011).

\footnotetext{
${ }^{17}$ Por exemplo, ao explicar para o seu público de juristas como deveriam interpretar os testes de significância estatística, Sander escreve: "A estatística $t$ nos diz quão consistente ou confiável é uma relação, com uma estatística $t$ mais alta indicando uma associação mais forte, mais confiável. Estatísticas $t$ geralmente crescem como uma função do coeficiente padronizado e do tamanho da amostra. Estatísticas $t$ maiores do que 2.0 geralmente sinalizam que a variável independente realmente ajuda a prever a variável dependente. Uma estatística $t$ menor do que 2.0 indica uma relação fraca, inconsistente - que pode resultar de flutuações aleatórias nos dados" (Sander, 2004, pp. 428-29, ênfases minhas). Essa tentativa de esclarecer leitores das faculdades de direito sobre o significado das estatísticas $t$ sugere uma falta de entendimento fundamental sobre o que pode ser concluído a partir de testes de significância estatística. Ver, por exemplo, Ziliak e McCloskey (2008).

${ }^{18} \mathrm{O}$ Professor Sander tem afirmado que seus resultados têm sido consistentemente replicados. Mas parece que, com isso, ele quer dizer que, quando pesquisadores partem doa mesmos pressupostos que os seus, utilizam os mesmos dados, modelos e abordagens estatísticas, chegam aos mesmos resultados que ele. Isso evidencia que ele descreveu seus resultados de modo preciso, mas em nenhum outro sentido significa replicá-los. Se seus achados fossem robustos, eles deveriam manter-se, mesmo sob diferentes pressupostos plausíveis, quando outros modelos plausíveis fossem utilizados e quando sua abordagem estatística fosse melhorada. As tentativas de replicação que tentam fazer isso, não só não conseguem confirmar seus resultados, como produzem, com frequência, resultados mais consistentes com o oposto da hipótese da disparidade.
} 
Camilli e seus colegas (2011), assim como Rothstein e Yoon (2008) apresentam resultados mais matizados, pois, embora não tenham encontrado evidências dos efeitos da disparidade entre estudantes negros cujas qualificações iniciais os colocavam entre os primeiros $80 \%$ de todos os estudantes das faculdades de direito, encontraram indícios de que a disparidade prejudicaria alguns estudantes colocados entre os $20 \%$ menos qualificados entre todos os matriculados. Uma vez que $75 \%$ dos afro-americanos admitidos nas faculdades de direito em 1991 estavam entre os $20 \%$ menos qualificados, pode parecer que as afirmações de Sander se sustentam, mas, na verdade, esses estudos fornecem pouco alento para os defensores da hipótese da disparidade. Primeiro, o grau de disparidade nas qualificações de ingresso naquelas faculdades de direito dos estratos mais seletivos é tão grande ou maior do que aquele nos estratos menos seletivos, e ademais, os dois estratos com as médias mais elevadas de qualificações de admissão têm muito poucos estudantes afro-americanos colocados no quintil inferior de todos os alunos. Em segundo lugar, Camilli et al. examinaram separadamente os grupos de indígenas, hispânicos, afro-americanos, asiáticos e brancos. Deixando de lado a classificação dentro das turmas, eles encontraram evidência consistente com a hipótese da disparidade apenas ao examinar alguns resultados para negros e asiáticos. Além disso, quando a evidência apontava na direção prevista, frequentemente não era estatisticamente significante e os efeitos estimados eram pequenos. Finalmente, a hipótese da disparidade não possui um componente étnico. Se a hipótese da disparidade explicasse o desempenho acadêmico, ela deveria valer para qualquer estudante cujo preparo para o curso de direito, medido pelas qualificações no ingresso, fosse substancialmente inferior ao de seus colegas. Não apenas não há evidência dos efeitos da disparidade entre os brancos com as piores qualificações, como também não existem sinais desses efeitos entre hispânicos ou indígenas 
com qualificações na mesma faixa, e ambos são grupos que se beneficiam da ação afirmativa. Assim, o estudo de Camilli et al. mais refuta do que sustenta a hipótese da disparidade, embora, em uma leitura superficial, possa parecer fornecer evidências coerentes com esta hipótese.

Rothstein e Yoon (2008) conduziram sua pesquisa sobre disparidade com o objetivo de avaliar a previsão de Sander de que, sem a ação afirmativa, haveria mais advogados negors formados. Sua abordagem envolve uma comparação relativamente direta entre estudantes de direito brancos e afro-americanos com qualificações similares e é auxiliada pela suposição simplificada de que todos os estudantes afro-americanos, mas nenhum estudante branco, estariam em condições de disparidade nas faculdades que frequentam. Sua lógica é de que algumas pessoas terão dificuldade em se graduar e/ou passar no exame da Ordem em razão de suas aptidões pessoais, refletidas nas qualificações de admissão, independentemente de estarem em condições similares ou díspares em relação aos outros nas faculdades que frequentam. Em seu modelo, os estudantes brancos, os quais não se beneficiam da ação afirmativa, constituem o padrão de comparação contra o qual é possível avaliar o grau em que os mesmos resultados possam ser esperados, independentemente de quão díspar ou similar for um estudante afro-americano em relação aos demais em sua classe. Eles não encontraram evidências para sustentar a hipótese da disparidade entre estudantes negros colocados entre os $80 \%$ mais bem qualificados entre todos os admitidos nas escolas de direito. Uma vez que quase todos os estudantes negros do BPS matriculados nas faculdades de direito mais seletivas do país qualificaram-se na admissão entre os $80 \%$ melhores, embora substancialmente abaixo da média das suas faculdades, esse achado é inconsistente com qualquer generalização da hipótese da disparidade.

Analisando todos os estudantes do BPS, Rothstein e Yoon descobriram que negros têm resultados piores do que os estudantes brancos em 
duas dimensões que afetam mais diretamente a produção de advogados negros - a graduação no curso de direito e, dependendo dessa, a aprovação no exame da Ordem. Devido, principalmente, ao baixo desempenho dos afro-americanos admitidos com qualificações entre as $10 \%$ mais baixas (58\% de todos os negros que se matricularam), os estudantes afro-americanos que ingressaram em cursos de direito tinham $11 \%$ menos probabilidade de se formar do que brancos e 18,3\% menos probabilidade de passar no exame da ordem, quando fizeram o exame. Contudo, após ajuste para as qualificações de ingresso, essas diferenças entre negros e brancos reduzem-se aproximadamente à metade, com a diferença nas taxas de graduação reduzindo-se a 6,4\% e a diferença de aprovação no exame da ordem, para 9,3\% ${ }^{19}$.

Rothstein e Yoon propõem esses últimos dados como um limite para os possíveis efeitos negativos da disparidade para os estudantes afro-americanos, mas são cautelosos, sugerindo que qualquer efeito real da disparidade pode estar muito abaixo deste limite. Eu acrescentaria que não necessariamente haverá inconsistência com os achados de Rothstein e Yoon se os efeitos adversos da disparidade sobre afro-americanos fossem zero, e que estão provavelmente perto disso. Assim, no BPS, as razões mais comuns dadas por estudantes para largar o curso de direito não são

\footnotetext{
${ }^{19}$ As diferenças na primeira tentativa do exame da ordem são mais desoladoras. Chegam a $29,1 \%$ na amostra não ajustada e a 14,5\% após ajuste para as qualificações de ingresso. Sander com frequência utiliza os dados de aprovação da primeira vez como sua variável dependente preferida, em boa parte, acredito, porque esta escolha corrobora melhor sua hipótese. No entanto, a aprovação no primeiro exame da ordem não determina o ingresso ou não de uma pessoa na prática profissional, e pode ser profundamente afetada por uma preparação adequada para o exame. Portanto, a riqueza e a natureza dos primeiros empregos podem explicar boa parte desses resultados. Estudantes mais pobres, entre os quais as minorias estão sobrerrepresentadas, podem decidir realizar o exame uma vez sem investir em um curso caro de preparação, para ver se tal investimento será necessário, e estudantes contratados por grandes firmas antes de realizar o exame, que são na maioria estudantes brancos, podem ganhar dispensa do trabalho para prepararem-se. Aqueles que precisam manter empregos de tempo integral, enquanto se preparam para o exame estarão em desvantagem.
} 
dificuldades acadêmicas, mas questões familiares e financeiras. Fatores culturais também podem influir, uma vez que estudantes negros provavelmente se sentem menos confortáveis que os brancos em faculdades de direito predominantemente brancas.

Com relação à aprovação no exame da ordem, Linda Wightman, a coordenadora do projeto BPS, descobriu que metade de toda diferença entre as taxas de aprovação de brancos e negros no exame da ordem pode ser atribuída à maior tendência dos brancos em refazer o exame quando eram reprovados (Wightman, 1997). Com relação a isso, os cursos de revisão para o exame podem ser caros, e muitos graduados precisam de um tempo considerável para estudar para o mesmo. As minorias podem ter menos condições de dispor tanto do tempo como de dinheiro. A essas considerações, Rothstein e Yoon acrescentam um problema estatístico. As disparidades encontradas por eles são puxadas por estudantes negros classificados entre os $20 \%$ menos habilitados de todos os selecionados pelas faculdades de direito e, especialmente, por aqueles entre os 10\% menos qualificados. Estudantes afro-americanos com históricos nesses níveis conseguiram ser aceitos nas faculdades de direito graças à ação afirmativa. Mas os estudantes brancos com qualificações similares, cujos resultados são utilizados para determinar os desvios ajustados, provavelmente tinham outros fatores a seu favor, incluindo indicadores de potencial acadêmico não detectados pelos escores do LSAT e pela média dos conceitos da graduação, pois, ao contrário dos afro-americanos, a maioria dos estudantes brancos com qualificações nesse patamar não conseguiria entrar em uma faculdade de direito. Portanto, parte das diferenças nas taxas de graduação e de aprovação no exame da ordem que persistem após o ajuste seria explicada pelo viés de seleção entre os alunos brancos e não pela disparidade dos alunos negros. Por fim, o estudo de Camilli et al. (2011) adverte sobre o equívoco em considerar demonstrada a hipótese da disparidade quando se analisa apenas o desempenho dos estudantes negros. 
Rothstein e Yoon também tentam simular os prováveis efeitos da admissão sem critérios raciais sobre o número de estudantes afro-americanos da coorte do BPS que teriam ingressado no curso de direito, se graduado e passado no exame. Eles estimam que, sob um sistema de admissão sem discriminação positiva de raça, o número de estudantes afro-americanos matriculados nas faculdades de direito do país teria caído 63\%, e a proporção de negros no total de estudantes admitidos teria caído de $8 \%$ para 3,1\% ${ }^{20}$ (Rothstein; Yoon, 2008, p.700). O número de estudantes afro-americanos frequentando faculdades rotuladas como de elite no BPS teria caído de 242 para 24. A maior queda numérica seria a perda de 646 estudantes (de 842 para 196) nas faculdades do terceiro estrato do BPS (na maioria universidades públicas) e uma queda de 436 (de 521 para 85) em faculdades de direito historicamente negras, cujos corpos discentes ainda abrigam, de longe, as maiores concentrações de estudantes afro-americanos do país (Rothstein; Yoon, 2008, p. 701). A mensagem implícita nesses dados é que, em termos de qualificações acadêmicas, mais da metade da coorte de estudantes afro-americanos que ingressaram nos cursos de direito em 1991 estaria em disparidade com os demais estudantes em qualquer faculdade de direito. Mas a maioria desses estudantes graduou-se e passou no exame da ordem. Os resultados simulados também são irônicos. Os dois estratos do BPS que perderiam o maior número de estudantes negros são aqueles fora do estrato de elite, nos quais os afro-americanos teriam mais condições

\footnotetext{
${ }^{20}$ Esses números devem ser considerados hipotéticos e, talvez, como limites superiores extremos. Mesmo com admissões sem discriminação positiva de raça, as faculdades, através de esforços mais intensivos de recrutamento e com ponderação maior dos critérios que tendem a favorecer os negros nas admissões, podem evitar que sua população de estudantes negros caia aos níveis que ocorreriam se apenas escores em testes e histórico de notas fossem considerados. Além disso, os efeitos da admissão sem discriminação positiva de raça são sensíveis à mistura relativa de estudantes brancos e negros no grupo de candidatos a cada ano, e muito provavelmente teriam diminuído ao longo do tempo, porque as qualificações dos candidatos negros enquanto grupo têm melhorado, desde a coorte de 1991 do BPS, a um ritmo mais veloz do que as dos estudantes brancos.
} 
de saírem-se melhor do que o esperado em vista de suas qualificações, enquanto o quinto estrato do BPS, o único que ganharia estudantes negros, tinha, após ajuste para as qualificações, a menor taxa de sucesso em produzir advogados afro-americanos.

Sander tentou, de diversos modos, salvar suas alegações empíricas dos fracassos em replicá-las e do bombardeio de críticas que recebeu. Em resposta aos seus primeiros críticos, ele voltou a analisar os dados do BPS usando um método que tomou emprestado de Ayres e Brooks (2005), dois de seus críticos. Usando o método tomado de empréstimo, Sander (2005) procurou controlar o viés de seleção, comparando os resultados de estudantes negros que frequentavam a faculdade de direito de primeira opção, com os resultados dos negros que decidiram frequentar o curso que originalmente era sua segunda opção. Esta tentativa de controlar o viés de seleção baseia-se na suposição não testada de que a primeira opção de faculdade dos estudantes afro-americanos seria substancialmente mais seletiva do que a segunda opção que eles viessem eventualmente a frequentar. Essa suposição precisa ser verdadeira para que se possa aceitar a segunda suposição: se estudantes negros têm melhor desempenho em faculdades de segunda opção do que seus pares naquelas de primeira escolha, seria porque a disparidade entre eles e os demais estudantes da mesma faculdade é substancialmente menor ${ }^{21}$. Meus colegas e eu demonstramos os equívocos desta tentativa (Lempert; Kidder; Clydesdale;

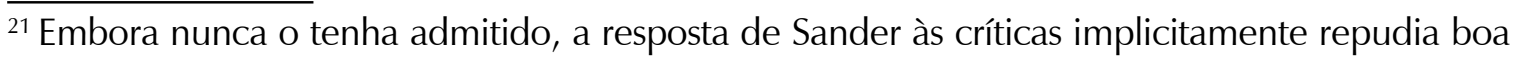
parte da análise apresentada em seu artigo original. Sander volta atrás em sua asserção de que a ação afirmativa reduz o número de advogados negros; ele aponta razões para a estrutura em estratos do BPS dificultar testes adequados para a teoria da disparidade, e sua ênfase e tentativa de controlar o viés de seleção implicitamente rejeita afirmações do artigo anterior, de que a admissão em faculdades de direito seria quase inteiramente função dos escores do candidato no LSAT e da média dos conceitos obtidos na graduação. Se isso fosse verdade, o viés de seleção, com exceção de possível autosseleção, quase não colocaria problemas, pois os pesquisadores poderiam controlar as variáveis que mais fortemente determinassem as decisões de admissão.
} 
Chambers, 2006; ver também Rothstein; Yoon, 2008, pp. 681-82.). Faculdades de segunda escolha são provavelmente similares em seletividade às primeiras opções. Então, qualquer diferença no grau de disparidade seria pequena, e parece que, no BPS, estudantes negros frequentando a faculdade de segunda opção eram, muitas vezes, academicamente mais fortes do que estudantes escolheram as mesmas faculdades como primeira opção ${ }^{22}$. Além disso, Sander comete um erro fundamental ao comparar seus estudantes afro-americanos da segunda opção a todos os estudantes negros, ao invés de compará-los ao subconjunto de negros aceitos em mais de uma faculdade de direito; ou seja, os estudantes "sem opção" podem ser particularmente fracos, enviesando, assim, a comparação de Sander, em favor do grupo da segunda opção.

Mais recentemente, Sander tentou reforçar seus argumentos em favor da teoria da disparidade referindo o trabalho de seu antigo co-autor, Doug Williams (Williams, 2013), mas este trabalho também é falho, de forma que pouco contribui (Kidder; Lempert, 2015). A análise que fundamenta o argumento de Williams elimina mais da metade dos estudantes negros na amostra do BPS, ignorando os estudantes das faculdades de direito dos dois estratos médios do BPS e, além disso, combinando faculdades de maneira a tornar a análise tendenciosa. Assim, faculdades dos dois estratos superiores são combinadas, embora as qualificações acadêmicas dos estudantes dessas faculdades sejam significativamente diferentes, enquanto as qualificações de estudantes do segundo estrato não são muito diferentes daquelas dos estudantes do terceiro estrato, que foi eliminado. Os dois últimos estratos são similarmente combinados, apesar de três quartos dos estudantes negros do grupo combinado frequentarem faculdades de direito

\footnotetext{
${ }^{22} \mathrm{~A}$ escolha da segunda opção parece ser motivada, geralmente, por considerações de ordem financeira e pela disponibilidade de programas de ajuda financeira mais atrativos na faculdade de segunda opção. Essas condições mais atrativas podem refletir qualificações especiais desses estudantes, vantagens que faltam a muitos candidatos que ficam com a primeira opção.
} 
historicamente negras. Tais faculdades, talvez porque forneçam ambientes mais acolhedores para os alunos negros devido à história ou a uma massa crítica de estudantes negros, formam muitos alunos negros cujo desempenho supera as expectativas baseadas em suas qualificações ${ }^{23}$.

Talvez a melhor síntese da consideração devida ao trabalho de Sander e Williams e, por extensão, à evidência empírica fornecida em apoio a hipótese da disparidade, seja encontrada não na usual literatura científica, mas em uma petição amicus curiae submetida à Suprema Corte (Empirical Scholars, 2012), com respeito ao caso Fisher v. University of Texas at Austin. Os signatários que avaliaram os dados e métodos de Sander e comentaram as contribuições de Williams incluíam respeitados especialistas em metodologia das áreas de economia, direito, ciência política, sociologia e estatística - dois deles (Gary King e Donald Rubin), membros da Academia Nacional de Ciências ${ }^{24}$. Esses especialistas, na maioria sem qualquer envolvimento anterior no debate sobre disparidade, concluíram:

[I]ndependentemente de se considerarem as conclusões de Sander altamente improváveis ou intuitivamente atrativas, sua pesquisa sobre "disparidade" falha em atender

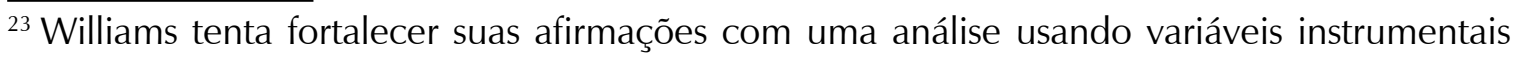
(VI), mas, embora o uso de técnicas de $\mathrm{VI}$ seja comum, os problemas inerentes a esse método são bem conhecidos. Nesse ponto, o melhor que posso fazer é citar Alon e Tienda: "O método mais usado [para controlar o viés de seleção], mas também o mais criticado, é o de correção através de variáveis instrumentais $(\mathrm{VI})$. As técnicas de $\mathrm{VI}$ apresentam três principais fraquezas. Primeiro, as suposições de validade das restrições de exclusão, em geral não são testáveis. Segundo, os erros padrão das estimativas de VI podem ser grandes se o instrumento for fraco. Terceiro, as Variáveis Instrumentais estimam de forma consistente o verdadeiro efeito médio de tratamento, apenas quando o efeito de tratamento é constante para todos os indivíduos [...].Além disso, Heckman et al. mostraram que usar Vls para avaliar os benefícios de participação em um programa produz estimadores bastante enviesados do impacto do programa, especialmente quando pessoas possuem informação privada (portanto não observada pelo analista) que é útil para prever os ganhos da participação no programa" (Alon; Tienda, 2005, p. 310; as citações internas que documentam essas limitações foram omitidas).

${ }^{24}$ Sou um dos signatários dessa petição. No entanto, não tive quase nenhum papel em sua redação, e também não me considero um "especialista em metodologia".
} 
os padrões básicos da boa pesquisa empírica em ciências sociais[...]. A falha de Sander em estabelecer controles adequados para testar sua hipótese, e sua dependência em uma série de suposições contraditórias o levaram a extrair inferências causais injustificadas. No mínimo, esses erros básicos de pesquisa suscitam questionamentos sobre as conclusões desta pesquisa (pp. 27-28)

\section{Disparidade científica}

Alguns oponentes da ação afirmativa, talvez frustrados porque tantos na comunidade acadêmica rejeitam suas afirmações empíricas, tentaram fortalecer seus argumentos com uma nova asserção; ou seja, a de que a ação afirmativa promove a "disparidade científica" (Sander; Taylor, 2011). Segundo esse argumento, os beneficiários da ação afirmativa, e particularmente os estudantes negros, ao entrarem na faculdade buscando uma carreira em ciências (science majors) ${ }^{*}$, engenharia ou matemática (aqui agrupados como "ciência"), estariam mais propensos a persistir até se formarem em um desses campos se suas qualificações fossem mais próximas daquelas de seus colegas interessados nos mesmos campos. Essa afirmação recebe mais apoio empírico do que a de um efeito de disparidade em geral (Elliott et al, 1996; Smyth; McArdle, 2004; Arcidiacono et al., 2013). A explicação é que estudantes pertencentes a minorias que almejam uma carreira científica são mais propensos a desanimarem-se e desistirem dela, se suas notas nas disciplinas de ciências forem menores do que as de seus colegas; e eles serão propensos a ter notas piores do

\footnotetext{
*Nos EUA, em nível de graduação, os estudantes ingressam na universidade, não em um curso específico, e só escolhem formalmente o curso específico (o major) depois, tipicamente no início do terceiro ano (de quatro), com os primeiros dois anos dedicados a uma formação geral, parcialmente diferenciada por grande área de conhecimento - ciência e tecnologia, ciências sociais (no sentido amplo) ou humanidades e artes. [Nota do organizador].
} 
que outros, quando seu preparo anterior - indicado pelas disciplinas cursadas no ensino médio (especialmente as de Colocação Adiantada, que facultam o ingresso direto em disciplinas mais avançadas na faculdade), pelo histórico escolar do ensino médio e pela pontuação no SAT, especialmente no exame de matemática - estiver abaixo daquele de seus colegas nas disciplinas de ciências. Isso é considerado mais provável se um aluno foi beneficiado com ação afirmativa, sendo admitido em uma faculdade apesar de qualificações acadêmicas substancialmente inferiores às da maioria dos outros alunos.

Há evidências sustentando essa linha de raciocínio, mas essas são mais sutis do que sugere o encadeamento lógico apresentado, e suas implicações para a política estão longe de ser claras. Primeiro, é importante saber que muitos estudantes interessados nas áreas científicas acabam mudando para outros cursos, independentemente de terem se beneficiado da ação afirmativa. Amanda Griffith (2010), trabalhando com dados de duas pesquisas nacionais - o National Education Longitudinal Study (NELS), com uma amostra de estudantes que iniciaram a faculdade em 1998 e o National Longitudinal Study of Freshmen (NLSF) ${ }^{*}$, com uma amostra de estudantes que iniciaram a faculdade em 1999 - relata que, nos dados do NELS, cerca de $52 \%$ dos estudantes não pertencentes a minorias que iniciaram a faculdade buscando graduação em ciências ${ }^{25}$ trocaram de curso antes

\footnotetext{
${ }^{*} \mathrm{O}$ termo freshmen refere-se aos alunos universitários de primeiro ano. [Nota do organizador]. ${ }^{25}$ Uma vez que muitos estudantes, em ambas as pesquisas, não especificaram sua preferência de curso quando perguntados pela primeira vez, Griffith definiu como intenção de carreira científica a menção de interesse em uma disciplina de ciências, engenharia ou matemática, ou um aluno ou uma aluna realizar mais da metade de suas disciplinas de primeiro ano nessas áreas. Contudo, há questionamentos sobre se esse ou outros estudos que focam em intenções de graduação em ciências estariam enviesando os resultados em favor da hipótese de disparidade científica. As minorias podem simplesmente ter uma ideia menos realista do que seja uma graduação em ciências, bem como um interesse acima da média em buscar estudos avançados em campos como medicina, que são vistos como fundamentais para a melhoria da renda e do status. Quando conhecem melhor as implicações de uma graduação nessas áreas,
} 
de seu último ano, sendo a percentagem equivalente para as minorias de cerca de $68 \%$. A diferença na taxa de desistência entre brancos e minorias é apenas um pouco maior do que entre homens (43\%) e mulheres (56\%), apesar de a ação afirmativa ter pouca influência nessa última diferença ${ }^{26}$. No NLSF, 69\% das minorias que ingressaram com interesse em ciências estavam em outros campos até o final do último ano, mas 52\% das não-minorias também havia trocado. A diferença entre homens e mulheres, no entanto, é menor nesse conjunto de dados. Cinquenta e sete por cento dos homens que iniciaram a faculdade com um interesse em ciências haviam trocado para outro campo até seu último ano (senior year), enquanto 64\% das mulheres haviam desistido da área da ciência. O ponto aqui é que minorias que iniciam a faculdade interessados em carreiras científicas, efetivamente mostram alta taxa de desistência, mas o mesmo acontece com todos os alunos que inicialmente pretendem se formar em um curso científico. Portanto, a maior parte das desistências da carreira científica por parte de minorias não pode ser atribuída à ação afirmativa.

Embora notas baixas estejam associadas à decisão de abandonar a pretendida carreira científica, o mecanismo pelo qual isso ocorre pode não ser a percepção de fracasso ao comparar-se com outros estudantes de ciência. O modelo de Griffith oferece uma perspectiva diferente. Ela

podem perder o interesse, enquanto estudantes brancos, seja porque conheceram mais cientistas desde a infância, ou porque cursaram disciplinas no ensino médio que proporcionaram mais informação sobre os conteúdos de um bacharelado em ciências, podem ter tido menor propensão em manifestar interesse em ciências no início da faculdade. Bowen e Bok (1998, p. 382), por exemplo, descobriram que proporções similares de brancos e negros na C\&B cursam graduação em ciências. Talvez, se eles tivessem examinado aqueles que acabam graduando-se em ciências, com relação àqueles que expressam esse interesse no início da faculdade, teriam concluído que os negros têm menos probabilidade de persistir na graduação em ciências do que os brancos.

${ }^{26}$ Outros estudos sugerem que mulheres pertencentes a minorias têm maior probabilidade do que as brancas de declarar que pretendem graduar-se em ciências, mas, dado o relativamente pequeno número de matrículas de minorias, isso não teria grande impacto na diferença entre homens e mulheres nas desistências informadas. 
descobriu que a razão entre as primeiras notas de um estudante em suas disciplinas de ciências e suas disciplinas não científicas tem um efeito significativo sobre a persistência ${ }^{27}$. Isso sugere ser a atração do êxito em disciplinas de ciências humanas e sociais, ao invés da repulsão provocada pelo insucesso nas disciplinas científicas, o que pode responder por boa parte das trocas de curso. Consistente com isso é a informação de Griffith de que $28 \%$ daqueles que abandonam graduações em ciências vão para um curso relacionado a alguma disciplina que cursaram durante seu primeiro semestre de faculdade. Além disso, pode-se compreender a razão de cursos não-científicos atraírem mais estudantes das minorias do que brancos, pois um curso como sociologia ou literatura inglesa difere dos cursos de ciências exatas por oferecer várias disciplinas que focam em situações ou contribuições de minorias.

O trabalho de Arcidiacono et al. (2013) também é de interesse aqui. Eles tentam estimar para as minorias, dependendo de um interesse inicial nas ciências, em que grau aumentaria a probabilidade de formar-se em ciências se, ao invés de frequentar a Universidade da Califórnia, Berkeley, UCLA ou UC San Diego, um estudante frequentasse uma das universidades menos seletivas do sistema da Califórnia - UC Santa Cruz ou UC Riverside. Para um estudante pertencente a minorias frequentando Berkeley, com escore SAT no quartil inferior do SAT (o exame nacio-

\footnotetext{
${ }^{27}$ Griffith não compara as notas em ciências entre estudantes que pretendem graduar-se em ciências na mesma instituição. Portanto, seus resultados não podem refutar a hipótese alternativa e, na medida em que as notas das disciplinas iniciais de ciências são atribuídas conforme uma curva (ou seja, dependem do desempenho relativo aos outros estudantes), o desempenho de outros estudantes de ciências terá impacto indireto no índice. Contudo, pesquisadores verificaram, também, que os conceitos nas disciplinas de ciências exatas são, em geral, mais baixos do que aquelas dos cursos de humanidades e outros. Assim, poderia ser a natureza da curva utilizada e especialmente seu centro, ao invés do lugar de um estudante na curva em relação aos outros estudantes, a principal propulsora da desistência da graduação em ciências. Notas mais baixas de maneira geral nas disciplinas de ciências e de matemática são consistentes com os achados de que muitos estudantes admitidos sem o benefício da ação afirmativa abandonam sua ideia inicial de graduarem-se em uma área das ciências exatas, engenharia ou matemática.
} 
nal padronizado de ingresso às faculdades de graduação), o modelo de Arcidiacono sugere que a probabilidade de se graduar em ciências seria 9,3\% maior se ele tivesse frequentado a Santa Cruz, e 10,1\% maior se frequentasse a Riverside. Para estudantes da UCLA, a chance estimada de um diploma em ciências seria 4,9\% maior na Santa Cruz, e 5,6\% maior na Riverside. Para aqueles matriculados na San Diego, a chance estimada de graduarem-se em ciências seria 0,2\% menor na Santa Cruz, e $2 \%$ maior na Riverside. Para estudantes pertencentes a minorias qualificados na admissão entre os $75 \%$ melhores de todos os matriculados no sistema da Universidade da Califórnia, a chance de se graduar em ciências - condicionada a um interesse inicial - mostra quase a mesma probabilidade de aumentar quanto de cair, caso frequentasse uma instituição menos seletiva. Em apenas um dos exemplos mudar para uma instituição menos seletiva aumenta em mais de $1,3 \%$ a probabilidade estimada de alcançar um diploma em ciência; e, em mais de 1/3 das trocas hipotéticas, a mudança para uma instituição menos seletiva está associada a uma probabilidade menor de persistência em um curso de ciências. Esses dados dificilmente dariam sustentação à hipótese de um efeito substancial da disparidade científica.

Além disso, ao considerar não a disparidade científica, mas a teoria de disparidade em sua versão geral, a simulação de Arcidiacono debilita ao invés de apoiar a alegação de que a ação afirmativa causa sérios problemas. Arcidiacono e seus colegas dividem seus dados por quartis de qualificações na admissão e pelo desejo ou não de uma graduação em ciências. Ao decompor os dados desse modo para prever os efeitos da mudança de Berkeley, UCLA ou San Diego para as universidades menos seletivas de Santa Cruz ou Riverside, eles produzem 16 comparações para cada universidade de origem. Para estudantes de Berkeley, a mais seletiva dessas universidades, em onze casos, a mudança para 
uma universidade de menor seletividade diminuiria a probabilidade de o estudante graduar-se, e em apenas cinco casos esta aumentaria. Para os estudantes da UCLA a situação é inversa, uma vez que dez das mudanças hipotéticas resultariam em uma probabilidade estimada maior de alcançar um diploma e seis delas resultariam em uma probabilidade menor. Apenas para San Diego, a menos seletiva das três universidades de origem, os ganhos esperados na probabilidade de graduar-se graças à mudança para uma universidade menos seletiva são sempre consistentes com a hipótese da disparidade. Mas os ganhos são pequenos normalmente 2,2\% ou menos e, nunca ultrapassando 3,2\%. Além disso, dada a provável maior disparidade em Berkeley e na UCLA, é improvável que a disparidade possa explicar os resultados para os alunos da UC San Diego. Características idiossincráticas daquele campus ou o puro acaso são explicações mais plausíveis.

Mesmo se a evidência de disparidade científica fosse muito mais forte do que efetivamente é, ainda seria um equívoco concluir que, eliminando-se a ação afirmativa, aumentaria a produção de cientistas afro-americanos ou de outras minorias. Para demonstrar isso, duas lacunas de pesquisa precisam ser preenchidas. Primeiro, como sugere a simulação de produção de advogados de Rothstein e Yoon (2008), seria preciso demonstrar que o maior sucesso desfrutado pelos que permanecem no sistema não seria mais do que anulado pela exclusão total de um número maior de estudantes se a ação afirmativa fosse abolida. Nos oito campi da Califórnia estudados por Arcidiacono e seus colegas, $15,9 \%$ dos estudantes pertencentes a minorias, com escores do SAT no quartil inferior e que ingressaram na faculdade buscando graduação em ciências, efetivamente graduaram-se nessa área dentro de cinco anos, como o fizeram $2,6 \%$ dos estudantes do quartil inferior que inicialmente não almejavam uma carreira científica (Arcidiacono et al., 2013, p. 13). 
Sem ação afirmativa, é provável que poucos ou nenhum desses estudantes pouco qualificados pudessem frequentar algum dos oito campi da Universidade da Califórnia. Mesmo se aqueles estudantes deslocados para campi menos seletivos completassem a graduação em ciências a taxas mais elevadas, o sistema da universidade da Califórnia provavelmente estaria formando um número menor de pessoas pertencentes a minorias com um diploma em ciências ${ }^{28}$.

Em segundo lugar, para avaliar os efeitos da disparidade científica na produção de cientistas negros, é necessário acompanhar os estudantes após a graduação, uma vez que aqueles com bacharelado em ciências não necessariamente buscarão carreiras científicas. Sabendo que as carreiras científicas, especialmente cargos em engenharia ou técnico-científicas de nível médio, estão disponíveis para aqueles com diplomas em todos os níveis, não deixa de ser instrutivo considerar o topo da cadeia científica - aqueles com PhD que constroem suas carreiras no ensino superior e em pesquisa. Um estudante pertencente a uma minoria, que estuda ciências em uma universidade como Berkeley, provavelmente estará em um departamento que não apenas incentiva seus alunos a seguirem em direção a um doutorado, como está bem equipado para orientar e auxiliar os alunos que escolhem esse caminho. O estudante de Berkeley provavelmente terá também vários colegas que pretendem ser doutores em ciências e professores que servem de modelo de carreiras científicas exitosas. O mesmo estudante, em uma faculdade menos seletiva, terá menor probabilidade de estudar em um departamento que canaliza estu-

\footnotetext{
${ }^{28}$ Os dados só possibilitam uma avaliação superficial das prováveis mudanças dentro do sistema universitário da Califórnia. Alguns, se não a maior parte, daqueles dentre as minorias deslocadas completamente, entrariam no sistema da Universidade Estadual da Califórnia (menos seletiva que a Universidade da Califórnia), em universidades privadas ou em faculdades comunitárias. Não se sabe qual seria o impacto do deslocamento para essas instituições sobre as taxas de formação em ciências, assim como se desconhece a probabilidade de que a formação em ciências nessas faculdades viria a traduzir-se em empregos nesta área.
} 
dantes para instituições que conferem o PhD. Esse estudante terá, provavelmente, menos colegas que pretendem continuar sua educação científica, e professores menos exitosos do que esperavam quando alcançaram seu título de doutorado. A hipótese de que a ação afirmativa implicaria uma proporção menor de pessoas pertencentes a minorias persistindo até obter diplomas nas áreas científicas não ficou demonstrada de forma convincente. Mas, ainda que isso fosse verdade, os estudantes que persistem podem ter maior probabilidade de fazerem carreira em ciências e de obterem títulos de pós-graduação nas ciências, do que teriam caso tivessem frequentado as faculdades mais seletivas nas quais pudessem ingressar sem a ação afirmativa.

Do mesmo modo, ainda que a disparidade científica que pode ser atribuída à ação afirmativa estivesse reduzindo as taxas de conclusão dos cursos por minorias que buscavam uma graduação em ciências, não decorre daí que eliminar a ação afirmativa seria a melhor forma de resolver o problema. Elliot et al. (1996), no primeiro estudo que abordou de forma sistemática a possibilidade da disparidade em ciência, observou o extraordinário sucesso de faculdades e universidades historicamente negras em formar estudantes afro-americanos em áreas científicas e encaminhar cientistas afro-americanos rumo ao doutorado. Mas pode ser que isso não se dê em razão de os estudantes negros nessas instituições estarem academicamente mais assemelhados aos seus pares do que estariam se estivessem frequentando instituições mais seletivas, dominadas por brancos. A cultura pode ser mais importante para estimular a persistência no campo científico do que a paridade das qualificações acadêmicas. De forma consistente com essa possibilidade, Griffith, utilizando os dados do NLSF, verificou que as diferenças institucionais afetam a persistência de mulheres e de minorias nas áreas científicas. Tanto para as mulheres como para as minorias, assim como para os homens e para não-minorias, 
a persistência em um curso científico é mais provável se o estudante estiver em uma instituição "com mais alunos de graduação em relação aos pós-graduandos, bem como em instituições sem programas de pós-graduação", talvez porque "[i]nstituições com poucos pós-graduandos em relação ao total de alunos da graduação provavelmente tenham um foco maior no ensino de graduação" (Griffith, 2010, p.917). Griffith observou, também, uma relação curvilínea entre o financiamento da pesquisa científica e a persistência na obtenção de diplomas em ciências. A persistência por parte dos que buscam carreiras científicas é maior nas universidades e faculdades que dispõem de um nível moderado de financiamento para pesquisa, enquanto instituições com pouco ou nenhum financiamento para pesquisa, ou com bastante financiamento, possuem níveis menores de persistência nos cursos científicos. Além disso, Griffith observou, em consonância com a hipótese da disparidade científica, que as notas alcançadas nas primeiras disciplinas de ciências têm um impacto importante sobre a persistência, mas uma parte das diferenças nas taxas de persistência, que alguns atribuiriam à disparidade científica, é na verdade resultado das características institucionais. Berkeley e UCLA, por exemplo, têm uma razão pós-graduandos-graduandos elevada e um volume substancial de financiamento para pesquisa. Em Santa Cruz e Riverside, sem dúvida, esses dois indicadores são consideravelmente mais baixos.

Ademais, Elliot e colegas sugerem que programas especiais voltados às minorias com interesse em ciências podem aumentar a probabilidade de essas pessoas concluírem a graduação nesses campos. Se o objetivo é ampliar a produção de cientistas entre as minorias, as inovações e mudanças institucionais não só se apresentam como um caminho mais promissor que o de eliminar as ações afirmativas, como também impõe custos mínimos, se algum, sobre seus beneficiários. Estudantes que ingressam na universidade buscando um curso científico, mas que mudam para uma 
área diferente, não são desistentes. Ao contrário, graduam-se em cursos de ciências sociais e humanidades que lhes abrem portas para carreiras nas áreas do direito, de negócios/ administração, governo, forças armadas, entre outros setores. Se esses estudantes fossem desviados para instituições menos seletivas, não só a maior parte deles, de qualquer modo, não daria continuidade ao seu interesse nas ciências, como também, provavelmente, enfrentariam maiores dificuldades na carreira, em razão do menor prestígio das instituições em que estudaram (Dale; Kruger 2014).

\section{Ação afirmativa com base na classe}

Outro argumento trazido pelos oponentes da ação afirmativa com base na raça é o de que ela não é necessária. Argumenta-se, não que a diversidade racial no campus seja um objetivo incorreto, mas que, mesmo em relação a esse objetivo, a ação afirmativa com base na classe social seria um substituto adequado para admissões sensíveis à questão racial (Kahlenberg, 1996; Kahlenberg and Potter, 2012). Se a ação afirmativa com base na classe pudesse alcançar os mesmos objetivos de diversidade da ação afirmativa baseada na identidade racial, então as admissões sensíveis à questão racial seriam possivelmente inconstitucionais, pois não estariam de acordo com uma interpretação restritiva da 14aㅡ Emenda. Esse argumento, no entanto, como aqueles revisados no texto que antecede, não dispõe de apoio empírico suficiente. Embora a ação afirmativa com base em classe social possa justificar-se por si mesma, ela não serve como um substituto efetivo para a ação afirmativa de base racial.

Isso não surpreende. Embora os afro-americanos tenham probabilidade muito maior de serem pobres do que os brancos, numericamente os EUA têm muito mais pobres brancos, e o mesmo vale para os hispânicos. Richard Brooks conta-nos, por exemplo, que 50,7\% dos negros 
na base de dados do BPS, ou 936 estudantes, estão no último quartil de distribuição do status socioeconômico (SSE) da amostra. Apenas 22,3\% dos estudantes de direito brancos estão neste quartil, mas há 5.003 deles, superando em cinco vezes o número de negros com os mais baixos SSE (Brooks, 2005, p. 17). Além disso, ações afirmativas focadas na classe são menos eficientes para alcançar um dado nível de diversidade racial, pois estudantes mais fracos segundo a avaliação de suas qualificações terão que ser admitidos, em detrimento de outros estudantes do mesmo grupo étnico que parecem qualificados (Brooks, 2005; Fryer, Loury \& Yuret, 2008). Além disso, os recursos disponíveis para auxílio financeiro terão de aumentar, na medida em que mais estudantes dos estratos menos favorecidos da distribuição de renda e riqueza deverão frequentar universidades e faculdades seletivas. Portanto, na maioria das instituições seletivas, é muito limitado o grau em que ações afirmativas de natureza racial e com base na classe podem servir de substitutas uma da outra, se o objetivo é formar uma massa crítica de estudantes representantes de minorias (Cancian, 1998; Malamud, 1997).

Richard Kahlenberg é o mais proeminente acadêmico a adotar posição contrária. Baseado em um estudo de sua coautora, Halley Potter, sobre as principais universidades nos estados onde as ações afirmativas de caráter racial foram proibidas por lei ou decisão judicial, ele considera que uma combinação de atividades de divulgação direcionadas às minorias, ações afirmativas focadas na classe social e auxílio financeiro adicional possibilitará a matrícula de massas críticas de estudantes representantes de minorias, sem a necessidade de levar em consideração a raça (Kahlenberg; Potter, 2012). Examinei os dados em que Kahlenberg baseou-se, e cheguei a conclusões distintas, embora concorde com ele em um aspecto: todas as universidades e faculdades que ele e Potter examinaram seguiram esforçaram-se ao máximo para continuar a recrutar es- 
tudantes pertencentes a minorias depois da proibição de levar a raça em conta nos seus processos de admissão, e a ponderação de indicadores de classe social baixa foi incorporada à maioria dos protocolos de admissão. Portanto, a descrição de Potter das ações adotadas por cada universidade e os êxitos alcançados é uma maneira útil, embora imprecisa de avaliar alternativas às ações afirmativas. A seguir, teço comentários sobre cada uma das universidades que ela examina.

\section{Universidade do Texas e Texas A\&M University}

Em um esforço, que Potter não discute, a Universidade do Texas, em Austin, revisou a situação de suas matrículas de minorias depois do caso Grutter $^{29}$ e, com base em um rigoroso estudo da diversidade em salas de aula, concluiu que precisava complementar seu programa dos $10 \%$ melhores (dos alunos de cada escola de ensino médio no estado) com considerações explícitas de raça, para alcançar seus objetivos de diversidade. Essa avaliação é consistente com um estudo realizado por Harris e Tienda (2012). Buscando mudanças no tamanho das coortes da graduação, eles observaram que tanto na UT Austin como na Texas A\&M, apesar dos vários esforços desenvolvidos após a decisão do

\footnotetext{
${ }^{29}$ Devido a uma decisão de 1996, no caso Hopwood v. Texas, emitida pelo Quinto Juizado Federal de Apelações, as universidades do Texas e de alguns estados vizinhos foram proibidas de utilizar ações afirmativas de caráter racial. O caso Grutter anulou a decisão do Hopwood, uma vez que se aplicou nacionalmente. Assim, as universidades estaduais do Texas foram liberadas dessa proibição e podiam, novamente, considerar a raça como parte de um processo holístico de admissões. No período entre Hopwood e Grutter, a Texas procurara manter matrículas de minorias, através do que se tornou conhecido como o plano Texas 10\%. Qualquer estudante que se graduasse entre os dez por cento melhores de sua escola secundária teria admissão garantida na UT Austin ou em outra universidade estadual. Como muitas escolas secundárias do Texas tinham um corpo discente constituído quase inteiramente de estudantes de uma mesma origem étnico-racial, isso implicava que alguns estudantes daquela origem se qualificariam no plano de admissão dos dez por cento. Não importava se suas qualificações acadêmicas sugeriam que eles tinham menos possibilidades de um bom desempenho do que estudantes da mesma identidade racial que tivessem frequentado escolas mais integradas e não alcançado os dez por cento melhores de suas turmas.
} 
Hopwood para ampliar as matrículas de minorias, a desvantagem dos hispânicos em relação aos brancos nos processos de admissão havia aumentado. Eles concluíram que, mesmo em estados de elevada segregação como o Texas, onde os planos baseados em percentuais dos alunos das escolas de ensino médio têm maior probabilidade de aumentar as possibilidades de admissão para estudantes pertencentes a minorias, a ação afirmativa focada em raça constituía a política mais eficiente para a diversificar os campi universitários.

\section{Universidade da Califórnia Berkeley e UCLA}

Os dados de Potter indicam que, após a proibição das ações afirmativas na Califórnia, apesar da atenção às variáveis de classe e os esforços especiais para recrutar minorias, as matrículas de estudantes negros caíram em cerca de dois terços em Berkeley e cerca de 50\% na UCLA. Segundo Richard Sander (2012), a UCLA só conseguiu alcançar seu nível atual de estudantes afro-americanos através da atenção direta, ainda que dissimulada, à questão racial ${ }^{30}$.

\section{Universidade de Washington em Seattle}

Para a Universidade de Washington, em Seattle, os dados de Potter não revelam grande mudança na proporção de afro-americanos no campus depois da proibição das ações afirmativas, mas sua presença já era escassa, cerca de 3\%. Depois da proibição, essa proporção não aumentou, apesar de ter crescido em pelo menos $25 \%$ o número de afro-americanos

\footnotetext{
${ }^{30}$ Eu questiono esta conclusão. Tudo o que Sander consegue demonstrar é que há um número de candidatos negros cuja admissão não pode ser explicada pelas variáveis a que ele teve acesso. Robert Mare, utilizando informação um pouco melhor, também apurou que houve um número de candidatos negros cuja admissão não podia ser explicada por seu modelo, mas ele teve o cuidado de evitar a conclusão infundada de que isso significava que foi a raça desses alunos que fez a diferença na sua seleção.
} 
que concluíram o curso secundário no estado de Washington, embora a partir de um número inicial baixo. A proporção de hispânicos na UW-Seattle cresceu em relação ao que era antes de vigorar a proibição das ações afirmativas, mas o aumento proporcional nas matrículas foi menor do que o aumento no número de hispânicos que concluíram o curso secundário no estado. Além disso, a universidade ajudou a constituir, e aparentemente colaborou com um fundo privado que destina bolsas-auxílio a estudantes pertencentes a minorias. Se a ação afirmativa for considerada inconstitucional, esses programas de bolsas direcionadas a minorias étnico-raciais, mesmo de origem privada, poderiam também ser considerados inconstitucionais.

\section{Universidade da Flórida}

A Universidade da Flórida é o exemplo principal em apoio ao argumento de Kahlenberg. É a única universidade que exibe pouco ou nenhum impacto negativo da proibição das ações afirmativas sobre as matrículas de minorias. Potter observou que as matrículas de estudantes negros permaneceram constantes após a proibição, e as matrículas de hispânicos cresceram em conformidade com o aumento no número de hispânicos concluintes do segundo grau no estado.

\section{Universidade da Georgia}

Os dados da Geórgia são complexos. A Universidade da Geórgia exibe uma queda abrupta nas matrículas de estudantes negros após a decisão de Hopwood. Embora o estado da Geórgia tivesse deixado, alguns anos antes, de integrar a jurisdição do Quinto Juizado Federal e, portanto, não estivesse obrigado a acolher a sentença de Hopwood, parece que depois dela suas práticas de admissão na universidade mudaram de modo a conferir pouco ou nenhum peso ao fator racial, talvez antecipan- 
do que, como viria a ocorrer, o $11^{\circ}$ Juizado, ao deliberar sobre as ações afirmativas, tomaria uma posição parecida com a do 5 o Juizado no caso Hopwood. As matrículas de estudantes negros depois cresceram na Geórgia, chegando a um nível consideravelmente acima do que eram durante o breve período em o estado esteve legalmente proibido de considerar o fator racial. Mas, até 2011, último ano para o qual Potter dispõe de dados, elas ainda não haviam alcançado seus níveis anteriores ao caso Hopwood. Além disso, nos últimos anos, a proporção de hispânicos concluintes do segundo grau cresceu cinco vezes (a partir de um número inicial baixo), uma tendência que não se refletiu em um maior número de estudantes hispânicos na universidade ${ }^{31}$.

\section{Universidade de Michigan}

Os dados para a Universidade de Michigan colocam mais um embaraço à perspectiva otimista de Kahlenberg. Apesar dos esforços para manter as matrículas de minorias, a faculdade de graduação experimentou uma queda acentuada nas matrículas de afro-americanos, depois que seu processo de seleção, que dava pontos adicionais aos candidatos oriundos de minorias, foi declarado inconstitucional no caso Gratz. As matrículas de afro-americanos cresceram um pouco quando a faculdade de graduação mudou seu sistema de admissão para um processo mais holístico, que possibilitava levar em consideração a raça do candidato. Mas, depois do plebiscito que aprovou a Proposição 2 do estado de Michigan, que proibiu ações afirmativas baseadas na raça, o número de estudantes negros que aceitavam as ofertas de ad-

\footnotetext{
${ }^{31}$ Parece que os dados pertinentes do relatório de Kahlenberg e Potter confundem os números de negros e de hispânicos, pois é difícil acreditar que os concluintes hispânicos da escola secundária na Geórgia superariam os concluintes negros por uma razão de 7 para 1 .
} 
missão caiu em quase um terço ${ }^{32}$. Além disso, enquanto ocorria essa queda pós-Gratz nas matrículas de afro-americanos, a proporção de desses estudantes que concluíam o segundo grau estava crescendo em quase um terço. Na Faculdade de Direito, que venceu em Grutter, mas teve suas políticas de admissão revogadas pela Proposição 2, a proporção de ingressantes afro-americanos caiu pela metade ou mais ${ }^{33}$. Isso ocorreu apesar dos consideráveis tempo e recursos despendidos tanto pela faculdade de graduação quanto pela faculdade de direito para estimular estudantes negros a candidatarem-se, e de ambas considerarem outros fatores que não a raça, os quais teriam maior probabilidade de caracterizar os candidatos afro-americanos do que os brancos.

\section{Universidade de Nebraska}

A Universidade de Nebraska, em Lincoln, é a última universidade em um estado que proíbe ações afirmativas ${ }^{34}$, para a qual Potter fornece dados. A proporção de afro-americanos no campus, que nunca chegou a $3 \%$, não mudou muito com a abolição das admissões sensíveis à raça, embora a proporção de concluintes afro-americanos das escolas secundárias do estado tenha crescido em cerca de um terço, de $6 \%$ para $8 \%$ no período. Assim, esse é outro estado para o qual parece que, na medida em que as matrículas de minorias tenham se mantido, as alternativas baseadas na

\footnotetext{
${ }^{32}$ Não se pode atribuir necessariamente toda a diminuição das matrículas à impossibilidade da universidade levar em consideração o fator raça. É possível que os estudantes afro-americanos aceitos tenham percebido o campus como pouco amigável e escolhido ir para outra universidade. Mas desconheço estudos que abordem essa possibilidade.

${ }^{33}$ Esta informação não foi extraída de Kahlenberg e Potter. Tenho conhecimento dela como um professor emérito da Faculdade de Direito da Universidade de Michigan que, ocasionalmente, faz contato com o departamento de admissões.

${ }^{34}$ New Hampshire e Arizona também aboliram as ações afirmativas de caráter racial, mas na época em que Kalhlenberg e Potter produziram seu relatório essas ações eram ainda muito recentes para permitir análises das tendências resultantes.
} 
classe social e outros esforços especiais provavelmente respondem menos pela manutenção das matrículas de minorias do que o aumento percentual do conjunto de potenciais candidatos das minorias.

\section{Estudo no Colorado}

Observando os diferentes resultados em distintos estados, e considerando os muitos estados em que se ampliou, em alguns casos substancialmente, a proporção dos diplomas de segundo grau concedidos a minorias, pode-se questionar como Kahlenberg pode ver nos dados coletados por Potter um forte fundamento para sua asserção de que as ações afirmativas baseadas na classe social podem gerar os mesmos níveis de diversidade racial do que as admissões sensíveis à raça.

No entanto, Kahlenberg dispõe de um bom estudo que pode citar para sustentar sua proposição. Trata-se de um artigo de Gaertner e Hart (2013) que relata os esforços desses autores para desenvolver uma abordagem baseada em classe social para manter o nível de matrículas de minorias na Universidade de Colorado, quando parecia que os eleitores do estado iriam seguir aqueles de outros estados e, por plebiscito, proibir as ações afirmativas. Embora o plebiscito tenha perdido, ele proporcionou aos pesquisadores uma oportunidade para testar seu modelo. Sua abordagem consistiu, essencialmente, da criação de dois índices - um que media a desvantagem relativa e o outro um "índice de alto desempenho", que media o grau em que o desempenho de um candidato no curso secundário ultrapassava as expectativas para um aluno em suas circunstâncias. Os candidatos ganhavam uma prioridade maior na admissão, se apresentassem a desvantagem relativa, e mais prioridade ainda, caso suas circunstâncias indicassem um alto grau de vulnerabilidade. De modo similar, ganhavam na escala de prioridades, se, comparados ao desempenho no ensino médio previsto por um modelo estatístico, eles tivessem 
ultrapassado em certo grau essa expectativa, e uma prioridade maior, se o seu desempenho estivesse muito acima do esperado. Quando um candidato adquiria maior prioridade pelos dois critérios, sua chance de admissão era alta e, se uma das prioridades fosse substancial, sua admissão era praticamente certa.

Gaertner e Hart testaram primeiramente o funcionamento de seu modelo utilizando uma amostra aleatória de candidatos já admitidos e, no ano seguinte, depois do fracasso do plebiscito, utilizaram uma amostra de 2.000 candidatos liminares para tomada de decisões efetivas de admissão. Os resultados indicaram que, sem considerar o fator raça, não só o sistema operou melhor do que sistemas sensíveis à raça para admitir minorias sub-representadas, como também admitiu mais estudantes com status socioeconômico mais baixo, deu um considerável impulso às chances de admissão de minorias com baixo status socioeconômico e teve impactos mínimos na qualificação média da universidade, a qual afeta de forma importante seu status na classificação feita pelo US News ${ }^{35}$. Quando o sistema foi agregado a procedimentos que possibilitavam atribuir certo peso ao fator raça, as chances de admissão de minorias sub-representadas cresceram ainda mais. Isso parece ter ocorrido, em grande medida, porque as comissões de seleção sentiram-se mais livres para atribuir vantagens relacionadas à classe social quando os candidatos provinham de minorias sub-representadas.

\footnotetext{
${ }^{35} \mathrm{O}$ impacto mínimo não surpreende. Só uma pequena fração dos admitidos pertencia a minorias sub-representadas e, para ser considerado, seja mediante ação afirmativa de raça ou de classe, um candidato precisa apresentar qualificações que superem um padrão mínimo estabelecido. Além disso, na sua classificação, o U.S. News utiliza a mediana dos escores ao invés da média. Mesmo admitindo um número relativamente alto de estudantes com qualificações de ingresso muito baixas, isso terá pouco impacto sobre a mediana, uma vez que os candidatos preteridos em favor da ação afirmativa são em geral aqueles com qualificações que estão abaixo da mediana para todos os selecionados.
} 
Apesar do cuidado com que eles desenvolveram suas fórmulas e do êxito de seus experimentos, os autores são cautelosos para não exagerar o que conseguiram fazer. Eles observam, por exemplo, que candidatos admitidos em razão de considerações de classe, quando teriam tido sua admissão negada se o fator raça constituísse o único critério para conceder vantagens, tinham no conjunto, qualificações de admissão muito baixas, pouco acima do mínimo aceito para admissão. Podia-se supor, portanto, que esses estudantes - embora poucos - enfrentariam dificuldades maiores em seus estudos ${ }^{36}$. Além disso, os autores observam que o que funcionou no Colorado não necessariamente funcionaria em outros estados. A Universidade de Colorado admite 84\% daqueles que se candidatam, portanto é pouco seletiva, e a vantagem que historicamente concedeu às minorias nunca foi grande. Isso significa que, no Colorado, diferentemente de muitos estados, o efeito de substituir um sistema baseado na raça por um com base na classe social não teria reduzido substancialmente as chances de um estudante de uma minoria ser admitido ainda que a classe não estivesse correlacionada com a raça. A avaliação geral dos autores é de que, mesmo utilizando seu instrumento, a ação afirmativa com base na classe não pode substituir aquela de caráter racial, embora o instrumento desenvolvido por eles possa ser um auxiliar valioso na tomada de decisões para admissão.

\footnotetext{
${ }^{36}$ Se aceitássemos a teoria da disparidade, os estudantes que fossem admitidos em razão de considerações de classe, e que não seriam admitidos se a única vantagem concedida fosse apenas racial, seriam os últimos estudantes que as universidades deveriam admitir, pois seriam os mais díspares com relação a seus colegas de turma.
} 


\section{Conclusão}

Os argumentos em torno das ações afirmativas nos Estados Unidos têm sido tanto de caráter jurisprudencial quanto empírico. Neste artigo, procurei discutir de forma sucinta os casos judiciais relevantes e as questões jurisprudenciais. Focalizei de maneira central os debates empíricos em torno dos impactos das ações afirmativas com base em critérios raciais na educação superior e sobre a necessidade de considerar a raça, se o objetivo é melhorar a diversidade étnico-racial nos campi universitários. Ao fazer isso, examinei detidamente os argumentos levantados por oponentes das ações afirmativas, com especial atenção a três deles que têm figurado de modo mais destacado nos debates sobre a política e nos litígios constitucionais: os prejuízos supostamente causados pela disparidade acadêmica; a chamada disparidade científica, manifestada na falta de persistência das minorias dos cursos científicos; e a asserção de que as ações afirmativas com base na classe social podem substituir adequadamente as ações afirmativas raciais para assegurar a diversidade étnica e racial nos campi universitários.

Em nenhuma dessas áreas a pesquisa empírica que apoia as hipóteses de oponentes das ações afirmativas é convincente. Os argumentos que atribuem impactos nocivos à disparidade são baseados em estudos que exibem falhas metodológicas óbvias, e são desmentidos por vários outros estudos, muitos dos quais metodologicamente mais rigorosos. De fato, parece que os negros que enfrentam preconceitos implícitos ou explícitos no mercado de trabalho beneficiam-se bastante de frequentar instituições prestigiosas e altamente seletivas, muito provavelmente porque o fato de frequentar e graduar-se em instituições como essas compensa o estigma sutil que, de outro modo, é fixado a uma identidade racial negra.

$\mathrm{O}$ argumento de que as ações afirmativas baseadas em classe podem substituir aquelas de caráter racial para assegurar a diversidade é 
refutado pela experiência das universidades públicas mais seletivas, muitas das quais, depois da proibição da ação afirmativa racial, começaram a considerar indicadores de classe social. Além disso, é uma estratégia geral impraticável, tendo em vista o grande aumento dos auxílios financeiros que um sistema baseado simplesmente em classe exigiria. Não só os custos de manutenção das minoria admitidas por ações afirmativas aumentariam se os mais afluentes entre eles não fossem admitidos, como, para manter os números atuais de matrículas de minorias, esses números seriam igualados, ou mais provavelmente superados, pelos ingressantes brancos mais pobres, beneficiados por processos de seleção baseados unicamente na classe social, sem levar em conta a raça ${ }^{37}$. Por outro lado, estudantes pertencentes a minorias menos preparados e com status socioeconômico mais baixo teriam preferência na seleção sobre aqueles, também pertencentes a minorias, com melhores qualificações, mas que não partilham do baixo status de classe.

Apenas o argumento da disparidade científica encontra apoio empírico plausível, mas o alcance da afirmação parece um tanto exagerado. Muitos estudantes que afirmam, no início de suas carreiras universitárias, pretenderem uma graduação em ciências, e/ou começam a cursar disciplinas que são parte desses cursos, não persistem até concluir a graduação nessas áreas. A desistência é maior para as minorias do que para os estudantes brancos, mas uma boa parte dela não pode ser atribuída às ações afirmativas, porque as mulheres que, enquanto grupo, não se beneficiam dessas ações apresentam maiores taxas de desistência que os homens e,

\footnotetext{
${ }^{37}$ Há, evidentemente, boas razões para justificar que as faculdades e universidades de um país deveriam reduzir suas mensalidades ou ampliar os recursos de auxílio, de modo a possibilitar que mais estudantes oriundos de camadas pobres pudessem acessá-las. Podem-se levantar argumentos tanto de justiça social quanto de diversidade para o engajamento das universidades em mais ações afirmativas com base na classe social, mas isso não pode ser visto como um caminho alternativo para ampliar a diversidade étnico-racial, pois nem de longe traria os mesmos resultados que as admissões sensíveis ao fator raça.
} 
em alguns estudos, taxas bem maiores. As ações afirmativas e a chamada disparidade podem influir na desistência, porque um fator que a afeta são notas baixas relativamente às de outros estudantes. Presumivelmente, se algumas minorias estivessem em ambientes menos competitivos, elas alcançariam notas um pouco melhores e uma proporção maior persistiria até concluir a graduação. Mas os números provavelmente serão pequenos e, mesmo que suas qualificações acadêmicas fossem mais similares àquelas de seus pares brancos, muitas minorias ainda se sentiriam em desvantagem em relação aos brancos, em virtude de uma educação em ciências de qualidade inferior no ensino médio. Como um dado significativo, na pesquisa de Bowen e Bok, na coorte de 1989, a proporção de negros que se graduaram nas faculdades ou universidades seletivas cursando biologia, matemática, química ou engenharia foi, em cada campo, quase idêntica à proporção de estudantes brancos graduados nesses $\operatorname{cursos}^{38}$ (1998, p. 71). Não há muitas razões para acreditar que, se esses estudantes tivessem frequentado instituições menos seletivas, teriam probabilidade maior do que seus pares brancos de graduar-se nessas áreas científicas.

Ao enfocar os argumentos empíricos levantados por oponentes das ações afirmativas e os estudos que citam por esses para reforçá-los, omiti em boa medida a discussão sobre os impactos positivos das ações afirmativas, não só sobre as minorias étnico-raciais beneficiadas por preferência nas admissões, como também para a população branca, a qual ganha uma educação integrada e também uma sociedade integrada quando aqueles com formação universitária ingressam no merca-

\footnotetext{
${ }^{38}$ Alguns, contudo, interpretaram esses dados como um indicativo do impacto da disparidade científica, porque inicialmente um número maior de afro-americanos havia expressado a intenção de fazer uma graduação em ciências. Mas esta diferença poderia facilmente ser atribuída ao fato de muitos negros terem uma imagem não realista sobre o que implicaria uma graduação em ciências, ou ao fato de serem atraídos para outras disciplinas consideradas mais pertinentes à para a experiência afro-americana, mas nunca estudadas no secundário.
} 
do de trabalho. Muitos estudos que evidenciam esses benefícios estão reunidos em AERA (2012), uma petição amicus curiae submetida à Suprema Corte em relação ao caso Fisher. De modo significativo, apesar do caráter testemunhal, duas das mais influentes petições amicus curiae apresentadas quando da decisão do caso Grutter foram submetidas por lideranças empresariais e militares, as quais atestaram a importância da ação afirmativa no ensino superior para a formação de uma força laboral diversa e da importância da diversidade na força de trabalho para o sucesso das empresas e das forças armadas na atualidade. De modo similar, qualquer pessoa que compare as ofertas de universidades e de faculdades de formação profissional de quarenta anos atrás com aquelas de hoje ficará impressionada pelo número de disciplinas, cursos e ofertas extracurriculares que provavelmente não existiriam, não fosse a presença de muitos beneficiários da ação afirmativa nos campi universitários. Isso é o que importa hoje em relação à ação afirmativa nos Estados Unidos. Ao avaliar as ações afirmativas, o mais importante não é evidenciar que as tentativas de prová-las contraprodutivas ou desnecessárias não resistem ao escrutínio científico, mas sim evidenciar a contribuição que essas ações têm trazido para a construção de uma sociedade racialmente mais igualitária e os benefícios disso para um sem número de americanos, independentemente de sua origem étnico-racial.

Richard Lempert é PhD. em Sociologia e Professor Emérito de Direito e Sociologia da Universidade de Michigan, Estados Unidos. \rlempert@umich.edu 


\section{Referências}

1. AERA. Brief of The American Educational Research Association et al. as Amici Curiae in Support of Respondents. In: Fisher vs. University of Texas at Austin. The Supreme Court of the United States. August 2012.

2. ALON, S.; TIENDA, M. Assessing the "Mismatch" Hypothesis: Differences in College Graduation Rates by Institutional Selectivity, Sociology of Education, Vol. 78 (October): 294-315, 2005.

3. ALON, S.; TIENDA, M. Diversity, Opportunity, and the Shifting Meritocracy in Higher Education, American Sociological Review, 72: 488-511, 2007.

4. ARCIDIACONO, P.; KOEDEL, C. Race and College Success: Evidence from Missouri, AEJ: Applied Economics, 6: (July 2014), 20-57, 2014.

5. ARCIDIACONO, P.; AUCEJO, E.; HOTZ V.J. University Differences in the Graduation of Minorities in STEM Fields: Evidence from California. Working Paper 18799. National Bureau of Economic Research. February, 2013. Disponível em: $<$ http://www.nber.org/papers/w18799.pdf>

6. AYRES, I. BROOKS, R. Does affirmative action reduce the number of Black lawyers? Stanford Law Review, 57, 1807-1854, 2005.

7. BOWEN, W.G.; BOK, D. The Shape of the River. Princeton, NJ: Princeton University Press, 1998.

8. BRAND, J.E.; HALABY, C.N. Regression and Matching Estimates of the Effects of Elite College Attendance on Educational and Career Achievement. Social Science Research. v. 35, n. 3, September 2006, pp. 749-770

9. BROOKS, R. Efficient Affirmative Action. 2005. Disponível em: <http:// www.law.yale.edu/documents/pdf/Efficient_Affirmative_Action.pdf $>$.

10. CAMILLI, G.; JACKSON, D.D. The Mismatch Hypothesis in Law School Admissions. Widener Journal of Law, Econ. \& Race, May 2011

11. CAMILLI, G.; WELNER, K.G. Is There a Mismatch Effect in Law School, Why Might It Arise, and What Would It Mean? Journal of College and University Law, 37, 491-527, 2011.

12. CANCIAN, M. Race-based Versus Class-based Affirmative Action in College Admissions. Journal of Policy Analysis and Management. 17(1):94-105, 1998.

13. CHAMBERS, D.L.; CLYDESDALE, T.; KIDDER, W.; LEMPERT, R. The Real Impact of Eliminating Affirmative Action in American Law Schools: an Empirical Critique of Richard Sander's Study. Stanford Law Review, 57, 1855-1898, 2005.

14. CORTES, K.E. Do Bans on Affirmative Action Hurt Minority Students? Evi- 
dence from the Texas Top 10\% Plan. Economics of Education Review, 29, pp. 1110-1124, 2010.

15. DALE, S.B.; KRUEGER, A.B. Estimating the Payoff to Attending a More Selective College: An Application of Selection on Observables and Unobservables. Quarterly Journal of Economics, v.117, n.4, 2002, pp. 1491-1527.

16. DALE, S.B.; KRUEGER, A.B. Estimating the return to college selectivity over the career using administrative earnings data. Journal of Human Resources, $v$. 49, 2014, pp.323-358.

17. DAUGHERTY, L.; MARTORELL, P.; McFARLIN Jr., I. The Texas Ten Percent Plan's Impact on College Enrollment. Education Next, Summer 2015, 63-69, 2014.

18. DAVIDSON, R.; LEWIS, E. Affirmative Action and Other Special Consideration Admissions at the University of California, Davis, School of Medicine. Journal of the American Medical Association, v. 278, pp.1153-1158, 1997.

19. De Funis v. Odegaard, US Supreme Court. 416 U.S. 312, 1974.

20. ELLIOTT, R.A. et al. The Role of Ethnicity in Choosing and Leaving Science in Highly Selective Institutions, Research in Higher Education, v.37, 1996, pp. 681-709

21. EMPIRICAL SCHOLARS. Brief of Empirical Scholars as Amicus Curiae Supporting Respondents. In: Fisher v. University of Texas. The Supreme Court of the United States. August 2012.

22. FISCHER, M.J.; MASSEY, D.S. The Effects of Affirmative Action in Higher Education. Social Science Research, v. 36, n.2, pp. 53I-549, 2007.

23. FRYER, R.G. Jr.; LOURY, G.C.; YURET, T. An Economic Analysis of Color-Blind Affirmative Action. Journal of Law \& Economic Organization, v. 24, pp.319-355, 2008.

24. GAERTNER, M.N.; HART, M. Considering Class: College Access and Diversity, Univ. of Colorado Law Legal Studies Research Paper No. 12-18. Disponível em: http://ssrn.com/abstract=2137126 or http://dx.doi.org/10.2139/ssrn.2137126

25. Gratz v. Bollinger. US Supreme Court. 539 U.S. 244, 2003.

26. GRIFFITH, A.L. Persistence of Women and Minorities in STEM Field Majors: Is It the School that Matters? Economics of Education Review 29: 911-922

27. Grutter v. Bollinger. US Supreme Court. 539 U.S. 306, 2003.

28. HARRIS, A.L; TIENDA, M. Hispanics in Higher Education and the Texas Top Ten Percent Law. Race and Social Problems, v. 4, n.1, pp. 57-67, 2012.

29. HO, D.E. Why Affirmative Action Does Not Cause Black Students Fail the Bar. Yale Law Journal, v.114, n.8, 2005, pp.1997-2004. 
30. Hopwood v. Texas, 78 F.3d 932 (5th Cir. 1996)

31. KAHLENBERG, R.D. The Remedy: Class, Race, And Affirmative Action. New York: Basic Books, 1996.

32. KAHLENBERG, R.D.; POTTER, H. A Better Affirmative Action: State Universities that Created Alternatives to Racial Preferences 9, Century Foundation Report, 2012. Disponível em: < https://tcf.org/assets/downloads/tcf-abaa.pdf.>

33. KIDDER, W.C. The Struggle for Access from Sweatt to Grutter: a History of African American, Latino, and American Indian Law School Admissions, 19502000, Harvard Black Letter Law Journal, 19, pp. 1-41, 2003.

34. KIDDER, W.C.; LEMPERT, R.O. The Mismatch Myth in US Higher Education: a Synthesis of the Empirical Evidence at the Law School and Undergraduate Levels. In: JAYAKUMAR, U.M.; GARCES, L.M. (Eds.) Affirmative Action and Racial Equity: Considering the Evidence in Fisher to Forge the Path Ahead. New York: Routledge Press, 2015.

35. LEMPERT, R.O.; CHAMBERS, D.L.; ADAMS, T.K. Michigan's Minority Graduates in Practice: The River Runs Through Law School, Law \& Social Inquiry, 25: 395-505, 2000.

36. LEMPERT, R.O. et al. Affirmative Action in American Law Schools: a Critical Response To Richard Sander's - "A Reply To Critics" (Working paper \#06-001), 2006. Arbor, MI: University of Michigan, John M. Olin Center for Law \& Economics. Disponível em: < http://www.law.umich.edu/centersandprograms/lawandeconomics/abstracts/Pages/06-001.aspx $>$.

37. MALAMUD, D. Assessing Class-Based Affirmative Action, Journal of Legal Education 47: 452 -471, 1997.

38. ORFIELD, G. (Ed.); KURLAENDER, M. Diversity Challenged: Evidence on the Impact of Affirmative Action. Cambridge, MA: Harvard Education Publishing Group, 2001.

39. PIKE, G.R.; KUH, G.D. Relationships among Structural Diversity, Informal Peer Interactions and Perceptions of the Campus Environment, The Review of Higher Education, Volume 29, Number 4, Summer, pp. 425-450, 2006.

40. PIKE, G.R.; KUH, G.D; GONYEA, R.M. Evaluating the Rationale for Affirmative Action in College Admissions: Direct and Indirect Relationships between Campus Diversity and Gains in Understanding Diverse Groups. Journal of College Student Development 48 (2): 166-182, 2007.

41. Regents of the University of California v. Bakke. US Supreme Court. 438 U.S. 265 (1978)

42. ROTHSTEIN, J.; YOON, A.H. Affirmative Action in Law School Admissions: What do Racial Preferences Do? University of Chicago Law Review, 75, 629-714, 2008. 
43. SANDER, R.H. A Systemic Analysis of Affirmative Action in American Law Schools. Stanford Law Review 57:367-483, 2004.

44. SANDER, R.H. A Reply to Critics. Stanford Law Review, 57, 1963-2016, 2005.

45. SANDER, R.H. The Consideration of Race in UCLA Undergraduate Admissions. October, 2012. Disponível em: <http://www.seaphe.org/pdf/uclaadmissions.pdf $>$.

46. SANDER, R.H.; TAYLOR Jr., S. Brief Amici Curiae for Richard Sander and Stuart Taylor, Jr. In Support of Neither Party. Fisher v. University of Texas. US Supreme Court. May 2012.

47. SANDER, R.H.; TAYLOR Jr., S. Mismatch: How Affirmative Action Hurts Fisher Students It's Intended to Help, and Why Universities Won't Admit it. New York, NY: Basic Books, 2012

48. SMYTH, F.L.; McCARDLE, J.J. Ethnic and Gender Differences in Science Graduation at Selective Colleges with Implications for Admission Policy and College Choice, Research in Higher Education, v. 45, n. 4, June, 2004, pp. 353-381.

49. SOWELL, T. Are Quotas Good for Blacks? Commentary, v.65, n.6, June 1978, pp.39-43.

50. SUMMERS, C.W. Preferential Admissions: an Unreal Solution to a Real Problem. University of Toledo Law Review 2(2-3), Spring-Summer: 377-402, 1970.

51. THERNSTROM, S.; THERNSTROM, A.M. America in Black and White: One Nation, Indivisible, New York: Simon \& Schuster, 1997.

52. TIENDA, M.; ALON, S.; NIU, S.X. Affirmative Action and the Texas Top 10\% Percent Admission Law: Balancing Equity and Access to Higher Education. Research Report, 2008. Disponível em: < http://theop.princeton.edu/reports/wp/ AffirmativeAction_TopTen.pdf>

53. WIGHTMAN, L.F. The Threat to Diversity in Legal Education: An Empirical Analysis of the Consequences of Abandoning Race as a Factor in Law School Admission Decisions. New York University Law Review, 72, 1-53, 1997.

54. WILLIAMS, D.E. Do Racial Preferences Affect Minority Learning in Law Schools? Journal of Empirical Legal Studies, 10(2), 171-195, 2013.

55. ZILIAK, S.T.; McCLOSKEY, D.N. The Cult of Statistical Significance: How the Standard Error Costs Us Jobs, Justice, and Lives. Ann Arbor: University of Michigan Press, 2008.

Recebido em: 17/01/2015

Aceite Final: 03/05/2015 